\title{
LOS HORNOS ALFAREROS DE TRADICIÓN FENICIA EN EL VALLE DEL GUADALQUIVIR Y SU PERDURACIÓN EN ÉPOCA ROMANA: ASPECTOS TECNOLÓGICOS Y SOCIALES
}

\author{
THE PHOENICIAN-TRADITIONS TRADITION KILNS IN THE GUADALQUIVIR VALLEY AND \\ THEIR PERSISTENCE IN ROMAN PERIOD: TECHNOLOGICAL AND SOCIAL ASPECTS
}

\author{
FRANCISCO JOSÉ GARCÍA FERNÁNDEZ \\ ENRIQUE GARCÍA VARGAS*
}

\begin{abstract}
Resumen: A principios de la Edad del Hierro se asiste en el sur de la Península Ibérica al asentamiento de colonos procedentes del Mediterráneo Oriental. Con ellos llegan también novedades tecnológicas, como el torno de alfarero o los hornos de tiro vertical. Ambas se difundieron rápidamente entre la población local, dada la resistencia del producto final y su adaptabilidad a distintas funciones. A la vajilla tradicional a mano se suma ahora un nuevo repertorio de mesa, almacenamiento y transporte heredero tecnológica, formal y estéticamente de la tradición oriental.

En el siglo V a.C. el torno y los hornos de tiro vertical se encontraban ya plenamente integrados entre los habitantes del valle del Guadalquivir. Desde un punto de vista socioeconómico se había pasado del modo de producción doméstico, característico de las comunidades aldeanas de finales de la Edad del Bronce, a un modo de producción artesanal, propio de una sociedad jerarquizada. Paralelamente, el repertorio cerámico había superado ya el proceso de hibridación formal y estaba perfectamente adaptada a las necesidades de la población: consumo, transporte, almacenamiento y cocina.

Con la conquista romana se introdujeron nuevos recipientes y algunas novedades gastronómicas que afectaron paulatinamente a la vajilla de mesa y a la cerámica de cocina. Sin
\end{abstract}

* Profesores del Departamento de Prehistoria y Arqueología de la Universidad de Sevilla, Facultad de Geografía e Historia, c/ María de Padilla s/n, 41004, Sevilla.

Este trabajo ha sido realizado en el marco de los proyectos "Sociedad y Paisaje. Economía rural y consumo urbano en el sur de la Península Ibérica (Siglos VIII a.C. - II d.C.)”, financiado por el
Zusammenfassung: $\mathrm{Zu}$ Beginn der Eisenzeit ereignete sich im Süden der Iberischen Halbinsel die Ansiedlung von Kolonisten aus dem östlichen Mittelmeerbereich. Mit ihnen kamen auch neue Technologien, wie die schnelldrehende Töpferscheibe oder die Rennöfen, die sich schnell unter der lokalen Bevölkerung verbreiteten. Dem traditionellen, handgefertigten Geschirr kommt jetzt ein neues Repertoire von Tisch-, Lager- und Transportkeramik hinzu, das sowohl technologisch als auch in ihrer Form und Ästhetik in der orientalen Tradition steht.

Im 5. Jh. v. Chr. befanden sich Drehscheibe und Rennöfen unter den Bewohner des Guadalquivir-Tals schon vollkommen integriert. Aus einer sozioökonomischen Perspektive bedeutete dies den Übergang von einer häuslichen Produktionsweise, die charakteristisch für die Dorfgemeinschaften der ausgehenden Bronzezeit gewesen war, zu der handwerklichen Produktion einer hierarchisierten Gesellschaft. Gleichzeitig hatte das Keramikrepertoire schon den Prozess der Hybridisation der Formen überstanden und war vollkommen den Bedürfnissen der Bevölkerung angepasst: Gebrauch, Transport, Lagerung und Küche.

Mit der römischen Eroberung wurden neue Gefäße und einige gastronomische Neuigkeiten eingeführt, die allmählich auch das Ess- und Kochgeschirr betrafen. Dennoch blieben 
embargo, las técnicas de fabricación y la estructura de los hornos se mantuvieron inalteradas en esta región incluso después de que buena parte de estos talleres pasaran a manos de inmigrantes itálicos. Los cambios que introdujo Augusto y el inicio Imperio afectaron a la propiedad, la ubicación y las dimensiones de los talleres (modo de producción esclavista), pero no a los aspectos técnicos de la producción, que se encontraban aún en manos de artesanos indígenas, herederos y transmisores de esta tradición alfarera.

Palabras clave: Alfarería, hornos, tecnología, púnicos, romanización, valle del Guadalquivir.

La cerámica ha sido usada durante mucho tiempo como un indicador cultural. A través de ella se han intentado rastrear influencias externas, cambios y perduraciones, formas de vida, etc. siendo considerada en no pocas ocasiones un marcador étnico, especialmente en los estudios sobre los pueblos de la Protohistoria. En el caso de la Península Ibérica algunos investigadores han tratado, por ejemplo, de definir las fronteras del área vettona a través de la cerámica con decoración a peine, en relación con la distribución de las esculturas zoomorfas de verracos (Ruiz Zapatero y Álvarez Sanchís 2002), mientras que las culturas de Cogotas o de Campos de Urnas quedaron estrechamente vinculadas desde su identificación a determinadas formas y técnicas decorativas distintivas. Del mismo modo, ha sido habitual dotar a los pueblos del Sur y Levante de caracteres étnicos o culturales a través de sus producciones cerámicas, usando también como base la morfología y la decoración, aunque pocas veces se ha reflexionado sobre la validez y sentido de tales reconstrucciones, sobre todo teniendo en cuenta la confluencia en esta región de sustratos y tradiciones diversas, así como la complejidad (y variedad) de procesos que se activan a partir de la llegada de los comerciantes y colonizadores orientales a principios de la Edad del Hierro.

Así pues, se ha asociado con frecuencia a los turdetanos con los pueblos del área ibérica a partir, principalmente, de las analogías en sus repertorios cerámicos, obviando las influencias comunes que los artesanos orientales ejercieron sobre las distintas tradiciones alfareras locales y las enormes diferencias que se observan en otros aspectos y facetas de su cultura, como es el caso de la lengua, las costumbres funerarias o las manifestaciones religiosas (Escacena 1989; 1992). Lo mismo ocurre con las poblaciones de las campiñas de Jerez y Cádiz, del litoral onubense o del Algarve, en su mayoría de origen púnico aunque consideradas comúnmente como turdetanas debido a su ubicación geográfica -dentro de die Fabrikationstechniken und die Struktur der Öfen in dieser Region unverändert, sogar nachdem ein Großteil der Werkstätten in die Hände von italischen Einwanderern übergegangen waren. Die Veränderungen, die Augustus und die Frühe Kaiserzeit einführten, betrafen zwar Besitz, Lage und Größe der Anlagen, aber nicht die technischen Aspekte der Produktion. Diese befanden sich noch in den Händen von einheimischen Handwerkern, den Erben und Übermittlern der Töpfertradition.

Stichwörter: Topferhandwerk, Topferofen, Technologie, punisch, Romanisierung, Tal des Guadalquivir

los límites históricos de Turdetania- y a las similitudes que sus producciones cerámicas, especialmente las formas comunes y con decoración pintada, guardan con las de los núcleos del interior del valle del Guadalquivir (Ferrer 1998; 2004). Como ya hemos puesto de manifiesto en anteriores trabajos (Ferrer y García Fernández 2002: 146; García Fernández 2007: 130), estas concomitancias entre las producciones cerámicas "púnicas", "turdetanas" e "ibéricas" resultan hasta cierto punto previsibles, si aceptamos que las tres son herederas de la matriz orientalizante, con todas sus particularidades locales, que son aquellas que precisamente explican las diferencias existentes entre unas zonas y otras.

En los últimos años hemos intentado desplazar el foco de atención desde el estudio singular de los tipos morfológicos y los motivos decorativos hacia el análisis de la composición cuantitativa y cualitativa de los conjuntos cerámicos, el uso de los distintos repertorios (transporte, almacenamiento, cocina, servicio) y su relación con las prácticas sociales que le dan sentido: tipos de alimentos, prácticas culinarias, formas de servicio y consumo, tanto en situaciones cotidianas como en contextos específicos (rituales, funerarios, etc.), que pueden adquirir eventualmente un carácter emblemático como reflejo de unas determinadas formas de vida (García Fernández y García Vargas 2010). Así pues, las formas cerámicas no delinean por sí mismas fronteras étnicas o culturales, sino que es su uso, es decir, su participación en las prácticas sociales, en el día a día de los individuos, las que les revisten de un significado que puede ser usado consciente o inconscientemente como expresión de una identidad individual o colectiva, no sólo étnica o cultural, sino también social, de género, etc. (García Fernández, e.p.).

El caso de las importaciones resulta especialmente paradigmático. La llegada durante los primeros años de la presencia romana de ánforas vinarias y vajillas de barniz negro procedentes de Campania no debe 
interpretarse automáticamente como el resultado de un proceso profundo de romanización de las comunidades receptoras. Antes bien, se trata de bienes de prestigio que van a adquirir valores específicos dentro de estas sociedades y que se acaban integrando de alguna manera en sus prácticas tradicionales, donde el vino y la vajilla asociada a su consumo habían jugado secularmente un importante papel en la alimentación y en las relaciones sociales (Jiménez y García Fernández 2006). Ello puede observarse claramente en los contextos republicanos de la antigua Spal (Hispalis), donde junto a las ánforas de vino arriban principalmente copas y platos en Campaniense A, formas que ya estaban presentes en los repertorios locales, bien en cerámica común como -en menor medida- en producciones gaditanas “tipo Kouass" (García Vargas y García Fernández 2009: 160). Sólo cuando se intensifica la presencia de inmigrantes itálicos a partir de finales del siglo II e inicios del I a.C. y comienzan a incorporarse formas de preparación y consumo propiamente romanas entre las poblaciones locales, se asiste a la llegada masiva de tipos y producciones nuevas, asociadas ahora a usos concretos: diversas formas de Campaniense $\mathrm{B}$, cerámica común $\mathrm{y}$ de cocina itálica, vasos de paredes finas, etc. (ibídem).

En estos momentos se observa también un cambio en la producción y distribución de los contenedores anfóricos en el valle del Guadalquivir. Frente a un panorama dominado por los envases de fabricación local o de procedencia púnico-gaditana (destinados tanto a salazones como a productos agropecuarios), donde se acaban incorporando progresivamente las ánforas de vino campano (Grecoitálicas y Dressel 1) y otros contenedores de origen norteafricano (Mañá D y Mañá C2), el tránsito al siglo I a.C. viene marcado por un cambio en los talleres sudhispanos, con la imitación masiva de estos tipos importados en detrimento de las formas locales y el desarrollo de nuevas variantes romanizadas (García Vargas 2009). Estas producciones estaban llamadas a satisfacer la creciente demanda de aquellos sectores de la población que no contaban con recursos suficientes para acceder a unos productos cuya popularidad no había dejado de crecer, aunque, sobre todo, fueron destinadas a cubrir las necesidades de abastecimiento de los principales cotos mineros (Sureste y Sierra Morena) y de los centros militares de la Península (García Vargas y Bernal 2008: 677).

Ambos fenómenos, cambios en la vajilla y la formalización de nuevos tipos anfóricos, están asociados, pues, a la llegada de nuevos contingentes poblacionales y a la paulatina "romanización" de las comunidades locales, que implica también la introducción de nuevos modelos productivos y formas de organización económica. La más llamativa de todas es la aparición de las villae y la generalización de la agricultura de plantación como modelo de explotación económica, que tiene su inicio precozmente en el entorno de la bahía de Cádiz a finales de la primera mitad del siglo I a.C. En efecto, las evidencias arqueológicas permiten suponer el establecimiento de inmigrantes romanos o de ciudadanos muy romanizados en el hinterland de Cádiz incluso con anterioridad a la concesión del estatuto municipal a esta ciudad por parte de César en torno al año 49 a.C. (Sayas 1989: 45). Resulta difícil concluir bajo qué fórmula se produjo el asentamiento de colonos en el interior de la campiña, si de forma privada, a través de la compra de fincas o el arrendamiento de tierras públicas, o bien mediante asignaciones, pero de lo que no cabe duda es que ello supuso la entrada de Gadir-Gades en el ámbito económico romano (García Vargas 1996: 56-57).

Una consecuencia de este fenómeno fue el traslado de los alfares destinados a la fabricación de envases anfóricos a los propios establecimientos rurales, toda vez que la explotación de los fundi comenzaba a ser rentable y se había consolidado la red de distribución y comercialización de los productos agrícolas (aceite y vino fundamentalmente). Prueba de ello es el hallazgo de varias instalaciones industriales en algunas de estas villae rusticas en la zona de El Puerto de Santa María y Puerto Real (ibídem), donde se elaboraban tanto tipos itálicos o de inspiración itálica (Dressel Ic, Dressel 12, Haltern 70), como contenedores de tradición púnica (Mañá C2b), que continuaban siendo en la costa gaditana los envases habituales para las salsas saladas de pescado durante el siglo I a.C. Estas instalaciones convivieron al menos durante un tiempo con los grandes centros industriales urbanos y suburbanos, destinados principalmente a la producción para la venta al exterior, algunos de los cuales se encontraban aún en manos de propietarios indígenas, como puede intuirse, por ejemplo, de los nombres consignados en los sellos hallados en el alfar de la c/ Gregorio Marañón de Cádiz (García Vargas 2004: 118). Asimismo, se observa la introducción de nuevas estructuras fornáceas, ahora de origen itálico, que alcanzarán un gran éxito y convivirán con los hornos de tradición fenicio-púnica, presentes en la región desde inicios de la Edad del Hierro.

En el valle del Guadalquivir y sus campiñas interiores el fenómeno de la villa no se extiende, por el contrario, hasta finales del siglo I a.C. o inicios de la Era, como resultado de la labor colonizadora emprendida por César y culminada con Augusto. Sólo a partir de ese momento los alfares abandonan paulatinamente los núcleos 
urbanos para trasladarse a los fundi, situándose en las proximidades de los principales cursos fluviales, en los lugares donde los productos procedentes de las distintas propiedades podían ser fácilmente envasados para su comercialización (Chic y García Vargas 2004: 319); aunque es probable que, al menos al principio, estos alfares siguieran trabajando de forma autónoma, es decir, funcionaran como talleres privados cuya producción iba destinada a su venta a los distintos possessores. Algunos de ellos estarán llamados a satisfacer no sólo la demanda de ánforas, sino también la de material constructivo y la de cerámicas comunes, cuya distribución, eminentemente local, está dirigida a las comunidades rurales. Sin embargo, como veremos a continuación, lejos de ser un proceso homogéneo y lineal, su desarrollo nos muestra una realidad llena de tentativas y matices, como reflejo de las diferentes transformaciones productivas y territoriales que se suceden en Turdetania desde mediados del siglo I a.C. y que se acelerarán gracias a las reformas económicas introducidas durante el principado de $\mathrm{Au}$ gusto, configurando el modelo territorial característico de la Baja Andalucía durante el periodo altoimperial. En este proceso el rol jugado por el sustrato local, y en especial por las elites urbanas, resulta determinante ya que es en los grandes centros del valle del Guadalquivir donde se inicia la adaptación de los espacios artesanales a las nuevas necesidades y oportunidades a las que se enfrentaba la comercialización de productos agrícolas, bajo el estímulo, eso sí, de los grupos itálicos que habían comenzado a instalarse en la región algunos años atrás.

El objetivo de este trabajo es, por tanto, valorar el peso del artesanado local en la organización y funcionamiento de los alfares del Bajo Guadalquivir en época romana a través del análisis de sus estructuras de producción, concretamente de la forma de los hornos y su localización, que es donde se aprecia de forma más meridiana el alcance de la influencia púnica -y turdetana- tanto en las técnicas de fabricación cerámica como en las estrategias de distribución y comercialización de sus productos. Para ello se realizará un recorrido por los diferentes talleres alfareros conocidos en el área de estudio, desde las primeras evidencias a inicios de la II Edad del Hierro y su evolución durante el periodo republicano, hasta su paulatina transformación en los primeros años del Imperio. Este recorrido nos llevará a lugares tan emblemáticos como Cerro Macareno, Itálica, Sevilla o Carmona, los cuales se encuentran por otro lado estrechamente vinculados a la labor investigadora del Prof. Bendala. Ello nos servirá de excelente excusa para rendir un sincero homenaje a su figura y a su valiosa aportación al estudio de la presencia púnica en el valle del Guadalquivir.

\section{EL HORNO DE PILAR CENTRAL: ORIGEN Y DIFUSIÓN EN LA PENÍNSULA IBÉRICA}

No vamos a detenernos en una descripción pormenorizada de la morfología de los hornos de pilar central, ya que es un aspecto sobradamente conocido que cuenta, además, con una abundante bibliografía (por ejemplo, Coll 2000). Indicaremos únicamente sus principales rasgos formales y funcionales con objeto de poder identificar las posibles variantes y rastrear su difusión y evolución en el área de estudio propuesta. Desde el punto de vista tecnológico, los hornos de pilar central se incluyen dentro de los hornos de tiro vertical, es decir, aquellos en los que la salida del humo se sitúa en la parte superior, generando una circulación ascendente del aire y del calor. Cuomo di Caprio distingue en su clasificación entre los hornos de pilar central sensu strictu (tipo I/a) y aquellos en los que el pilar se prolonga hasta convertirse en un muro axial que se adosa a la parte posterior de la cámara (tipo $\mathrm{I} / \mathrm{b}$ ), aunque con frecuencia ambos tipos pueden darse simultánea o consecutivamente en los mismos centros de producción, correspondiendo a dos soluciones posibles a un mismo concepto cuya estructura y funcionamiento son similares (Cuomo di Caprio 2007: 524).

Por lo que respecta a su forma, los hornos de pilar central presentan por lo general una planta circular de diámetro variable y una estructura tripartita compuesta por la cámara de combustión, la parrilla y la cámara de cocción o laboratorio. La primera, destinada a albergar y consumir el combustible, se encontraba generalmente semienterrada y ligeramente inclinada, con las paredes excavadas en el propio suelo y recubiertas de arcilla refractaria, lo que garantizaba tanto el mantenimiento de la temperatura como el control del aire que entraba en el horno. Para ello solía utilizarse la misma abertura a través de la cual se cargaba el combustible, y que podía adoptar eventualmente la forma de un pasillo más o menos largo cubierto con una bóveda de ladrillos de adobe. La cámara de combustión y la cámara de cocción estaban separadas por la parrilla, una superficie plana realizada también en adobe sobre la que se disponían los recipientes cerámicos. En función de su tamaño y espesor, ésta podía sustentarse directamente sobre las paredes de la cámara de combustión o con mayor frecuencia apoyarse en un pilar de adobe situado en el centro de la misma, constituyendo uno de los rasgos más característicos de estas estructuras. Una serie de orificios, distribuidos regularmente por toda la superficie de la parrilla, permitían el paso del calor y de los gases producidos por la combustión, 
evitando al mismo tiempo el contacto directo de los recipientes con las llamas. Por último, una cámara abovedada (cámara de cocción) cubría todo este espacio, manteniendo estable la temperatura y el ambiente en su interior. Solía construirse con ladrillos de adobe, conformando en ocasiones la única estructura visible del horno. No obstante, dependiendo de su envergadura, la cámara podía ser fija o móvil, es decir, podía construirse y retirarse en cada hornada con el fin de facilitar las labores de carga y descarga. De cualquier manera, contaba siempre con una o varias aberturas superiores destinadas a la salida del humo y los gases generados por la cocción (el tiro del horno), que podían manipularse con el fin de regular la misma. Asimismo, una puerta situada en un lateral servía para facilitar el acceso y la introducción de la carga, en el caso de los hornos de mayor tamaño, o simplemente para observar y controlar todo el proceso.

Este tipo de hornos aparece en diferentes culturas y periodos históricos a veces sin relación entre sí, aunque los especimenes que encontramos en la Península Ibérica, así como en otras áreas del Mediterráneo Central y Occidental a inicios de la Edad del Hierro, proceden directamente de los prototipos traídos por los colonos orientales, desarrollados en la costa sirio-palestina a finales de la Edad del Bronce (Falsone 1981: 27-35). No obstante, sus orígenes en Próximo Oriente son mucho más antiguos y se remontan a finales del IV milenio. De ahí probablemente se extendieron también hacia Asia Menor, Chipre, el Egeo y los Balcanes, dando lugar de forma paralela a las distintas variantes que convivieron en el Mediterráneo con los hornos de tradición fenicio-púnica a lo largo del I milenio a.C. Estos primeros prototipos orientales se caracterizaban por su particular forma de U, ya que la cámara de combustión estaba constituida por dos pasillos divergentes o ligeramente circulares separados entre sí por un murete de mampostería o adobe destinado a sostener la parrilla, como puede apreciarse en los ejemplares exhumados en Hazor, Tell Nashbesh Meggido o Sarepta (De frutos y Muñoz 1994: 396), de finales del II milenio a.C. (Sáez y otros 2004, fig. V). Durante el tránsito a la Edad del Hierro la planta de estos hornos va evolucionando hasta adoptar la típica forma de "omega" $(\omega)$ que se generalizará entre los siglos VIII al V a.C. con una cámara de combustión circular o ligeramente ovalada dividida en dos por el murete de sustentación. Este tipo será el que se exporte a las colonias fenicias del Mediterráneo Central y Occidental, como se observa en Mozia, en costa tunecina, en Kouass, o en las propias factorías de la Península Ibérica (Sáez y otros 2004, fig. IV).
Tal es el caso de las estructuras de alfar excavadas en Cerro del Villar, en la desembocadura del río Guadalhorce (Aubet y otros 1999). Las más antiguas -hasta ahora también de la Península- se localizaron en el extremo septentrional del yacimiento (sector 9) y estaban formadas por un horno cuya producción, tanto vajilla de mesa como grandes contenedores, permiten fechar su funcionamiento entre finales del siglo VIII e inicios del siglo VII a.C. (Delgado 2008: 78). Más espectacular es el taller hallado en la zona central (sector 3/4) donde no sólo pudieron documentarse varias estructuras de combustión de pequeño tamaño, situadas en este caso en un amplio espacio abierto pavimentado con guijarros, sino también un edificio de forma rectangular, dividido en dos compartimentos y destinado probablemente al modelado de los recipientes cerámicos, sobre todo ánforas (Curiá y otros 2000). Los abundantes materiales asociados a estas estructuras sugieren una producción a gran escala que podría situarse a principios del siglo VI a.C. y justo antes del abandono del asentamiento, entre los años 580 y 570 a.C. (Aubet 1999: 46).

Este tipo de hornos fue rápidamente adoptado por las comunidades indígenas más próximas a las colonias, como se aprecia en los alfares del Cerro de la Mora (Moraleda de Zafayona, Granada: Carrasco y otros 1987), el Cerro de los Infantes (Pinos Puente, Granada: Contreras y otros 1983), o La Campiña (Marmolejo, Jaén: Molinos y otros 1990; 1994), extendiéndose posteriormente durante la II Edad del Hierro hacia el área ibérica, donde se encuentra el extraordinario ejemplar de Alcalá del Júcar (Broncano y Coll 1988). Estos hornos reproducen las formas constructivas y técnicas productivas orientales, aunque introduciendo sensibles variantes en sus soluciones. Un caso singular lo tenemos en el pequeño establecimiento rural de La Campiña de Marmolejo, situado en el curso alto del Guadalquivir, donde se puso al descubierto un conjunto de hornos de finales del siglo VI a.C. destinado con probabilidad, al menos en parte, a la cocción de recipientes de cerámica gris orientalizante (fig. 1). Estas estructuras, que aparecen en algunos casos superpuestas unas a otras, se encuentran asociadas a otros espacios relacionados, aparentemente, con la manipulación o almacenamiento de las manufacturas. En todas se ha conservado únicamente la cámara de cocción, de planta circular en forma de "omega", pero realizada sobre una base o un zócalo de mampuestos irregulares y cantos de mediano tamaño que, posteriormente, serían forrados de adobe (Molinos y otros 1990: 198 ss.).

Ya en la zona de Cádiz, las excavaciones en el alfar de Camposoto (San Fernando) han ofrecido interesantes 


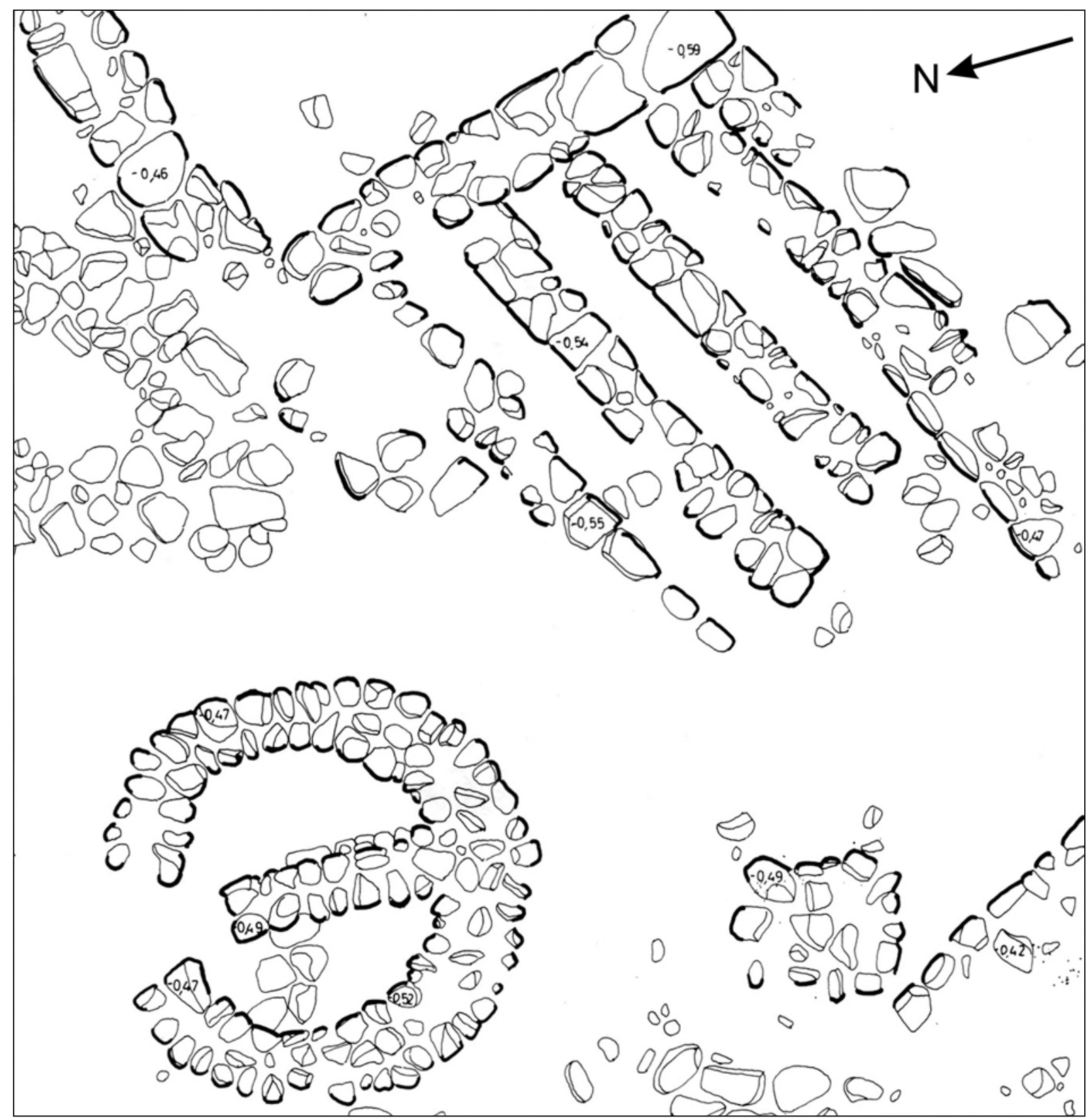

Figura 1: Instalación alfarera de La Campiña (Marmolejo, Jaén), según Molinos y otros 1990.

ejemplos de hornos de época tardo-arcaica (Gago y otros 2000; Ramón y otros 2007) que están sirviendo de ejemplo paradigmático para dibujar la evolución de las estructuras y formas productivas industriales fenicias en un momento de transición entre la I y la II Edad del Hierro (fig. 2). En esta ocasión nos encontramos ante un amplio conjunto de hornos, hasta siete en total, que aparecieron asociados en grupos funcionales en torno a fosas de trabajo semisoterradas donde se realizaban las tareas de alimentación, limpieza y reparación de las cámaras de combustión (Ramón y otros 2007:106-111). Tres de ellos presentan plantas circulares de tipo "omega", con un pilar central ovalado realizado en adobe y unido a la pared posterior de la cámara a través de un murete o contrafuerte; mientras que los otros cuatro, de forma y tamaño variable, cuentan ya con un pilar central exento o bien carecen del mismo, dadas sus reducidas dimensiones. En todos los casos 


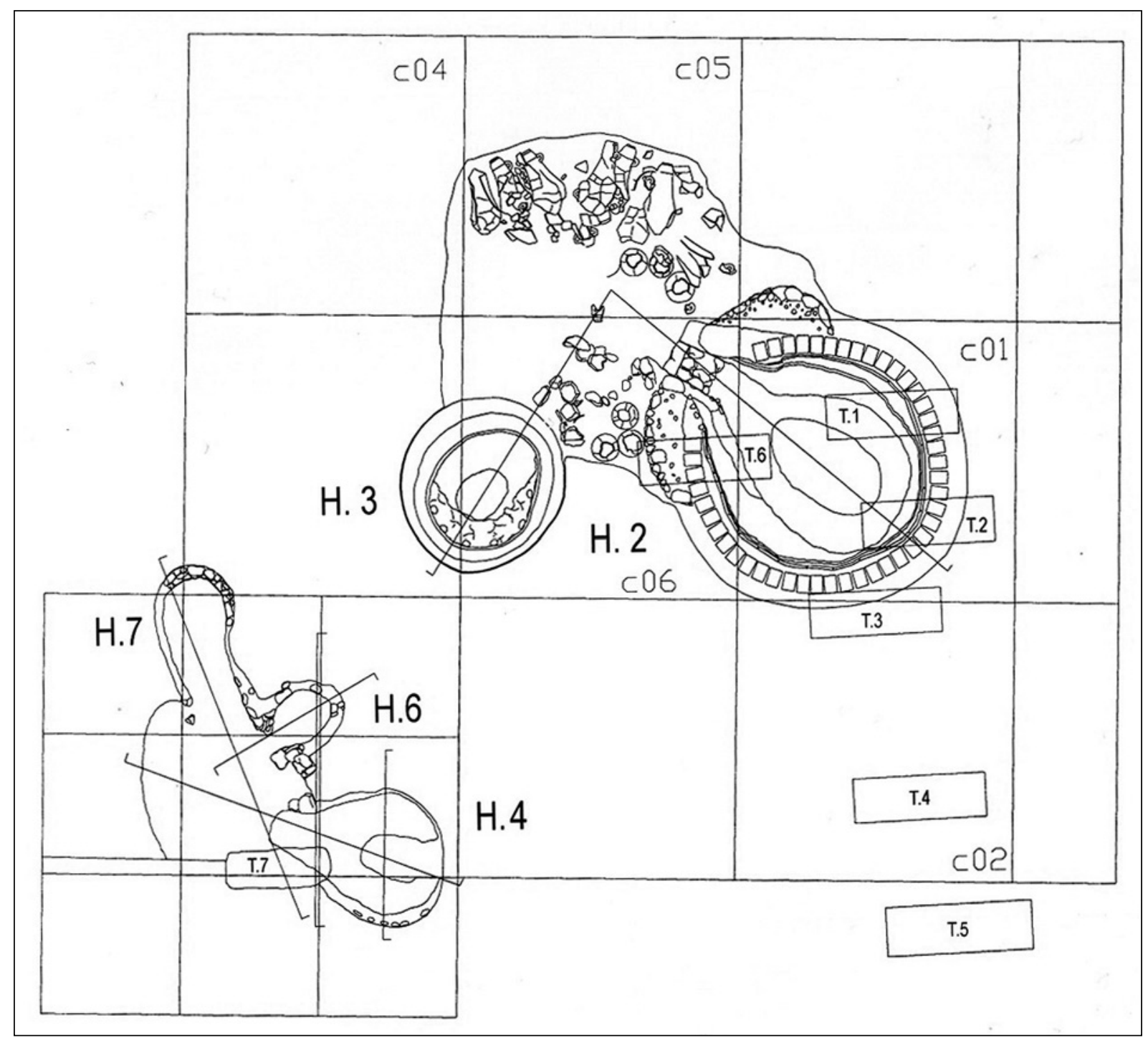

Figura 2: Hornos del Sector III-Camposoto (San Fernando, Cádiz), agrupaciones H2-H3 y H4-H6-H7, según Ramón y otros 2007.

están precedidos por un corredor de acceso alargado y siguen las mismas técnicas constructivas: excavación de una fosa semicircular en el suelo que a continuación era recubierta con argamasa de arcilla, con un aplacado de adobe o bien con un muro perimetral de uno o varios anillos, cuyo interior podía ser finalmente revocado con un mortero de cal y cerámica machacada. La cámara de cocción, que se ha conservado parcialmente en algunos casos, estaba construida con adobes dispuestos de forma horizontal, mientras que la parrilla se realizaba a base de adobe y argamasa de cal. Los hornos de mayor tamaño llevaban además la fachada reforzada con un muro de mampostería irregular, a base de piedra calcarenita trabada con arcilla y argamasa. La cronología que aportan los restos de producción (sobre todo ánforas T-11.2.1.3 de Ramón, así como pithoi, urnas, cuencos, etc.) nos sitúan entre la segunda mitad o último cuarto del siglo VI y mediados o tercer cuarto del V a.C. (Sáez 2011: 63). A estos primeros niveles sucederán a partir de la segunda mitad del siglo $\mathrm{V}$ a.C. otros expedientes constructivos documentados de forma fragmentaria pero relacionados también con la producción alfarera, prolongándose al menos hasta el siglo III, o incluso hasta los siglos II-I a.C. (ibídem: 63).

Un espécimen más evolucionado y un tanto insólito lo constituye el horno hallado recientemente en el centro de la ciudad de Málaga, junto a la Catedral, en el número 3 de la calle Císter (Arancibia y Escalante 


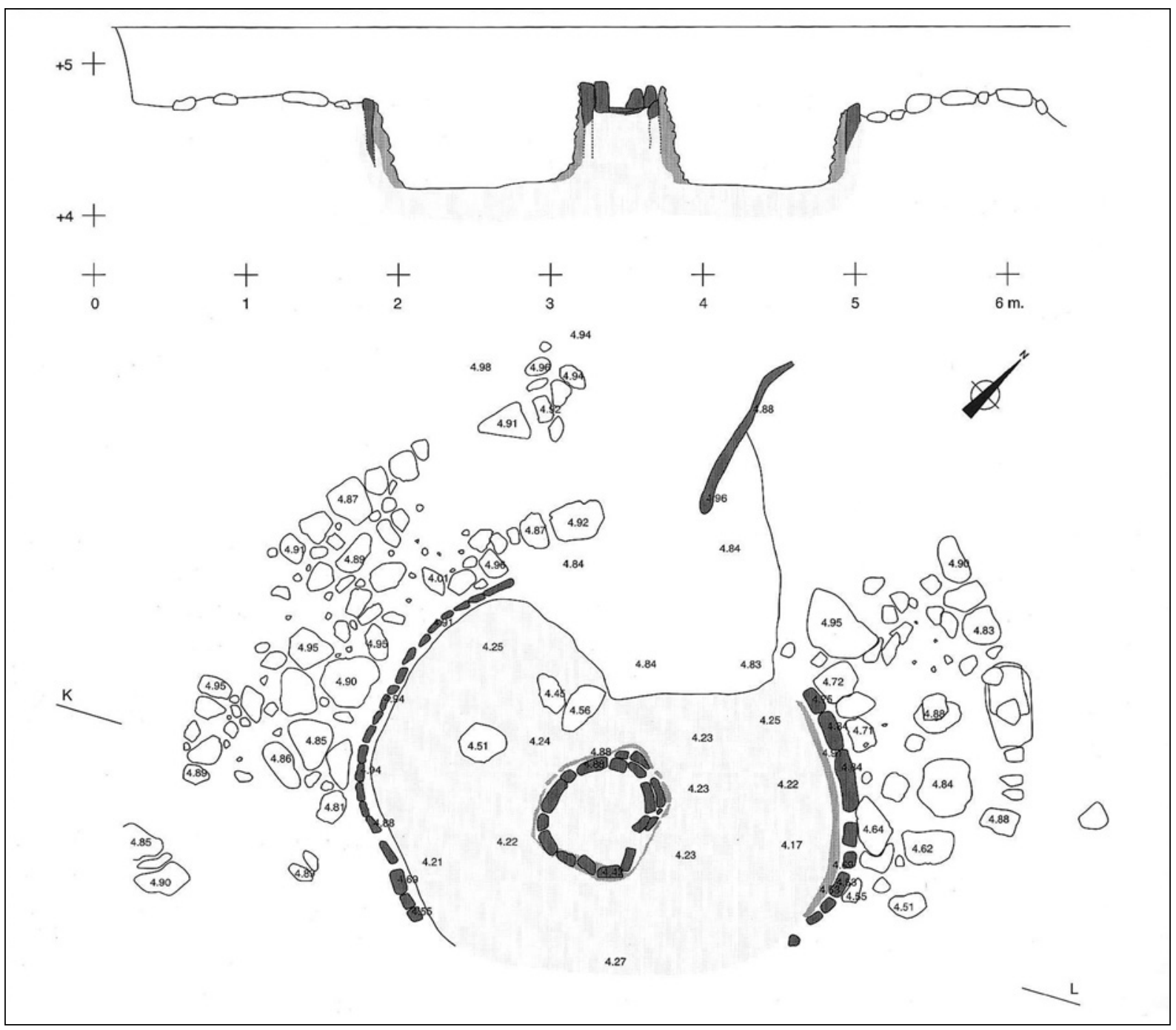

Figura 3: Horno Cerro del Villar (Málaga), sector 5, de según Aubet y otros 1999.

2006: 244-246). En un entorno aparentemente doméstico, se documentó el fondo de una estructura circular correspondiente a una cámara de combustión, excavada en el nivel geológico y recubierta de adobe, con la abertura del praefurnium orientada hacia el este. El elemento que le confiere este carácter singular es la aparición en el centro de la cámara de una cubeta rectangular de $1 \mathrm{~m}$. de largo por 0’50 m. de ancho, semiexcavada en su parte central y realizada igualmente en adobe. Ignoramos su cometido, ya que su estado de conservación tampoco permite conocer su desarrollo en alzado y su posible relación con la superestructura del horno. En cuando a su producción, actualmente en fase de estudio, parece que estaría orientada a diferentes clases cerámicas, incluidas las ánforas, entre las que se han podido identificar ejemplares evolucionados del tipo R-1, las primeras variantes del grupo MP-A4, platos de engobe rojo ya con pocillo, así como platos y cuencos de cerámica gris, entre otros.

Durante el siglo V a.C. estas estructuras evolucionan y adquieren definitivamente una forma circular $\mathrm{u}$ oval con la parrilla sostenida por un pilar central circular o rectangular, como puede verse en los alfares del norte de África (Utica, Kerkouane), de la bahía de Cádiz o del área turdetana (Sáez y otros 2004: 222). Una vez más el ejemplo más antiguo lo tenemos en Cerro del Villar donde, tras una fase de abandono de un siglo aproximadamente, se detectan de nuevo estructuras industriales vinculadas a la fabricación de envases anfóricos y otros recipientes cerámicos, aunque en este caso 

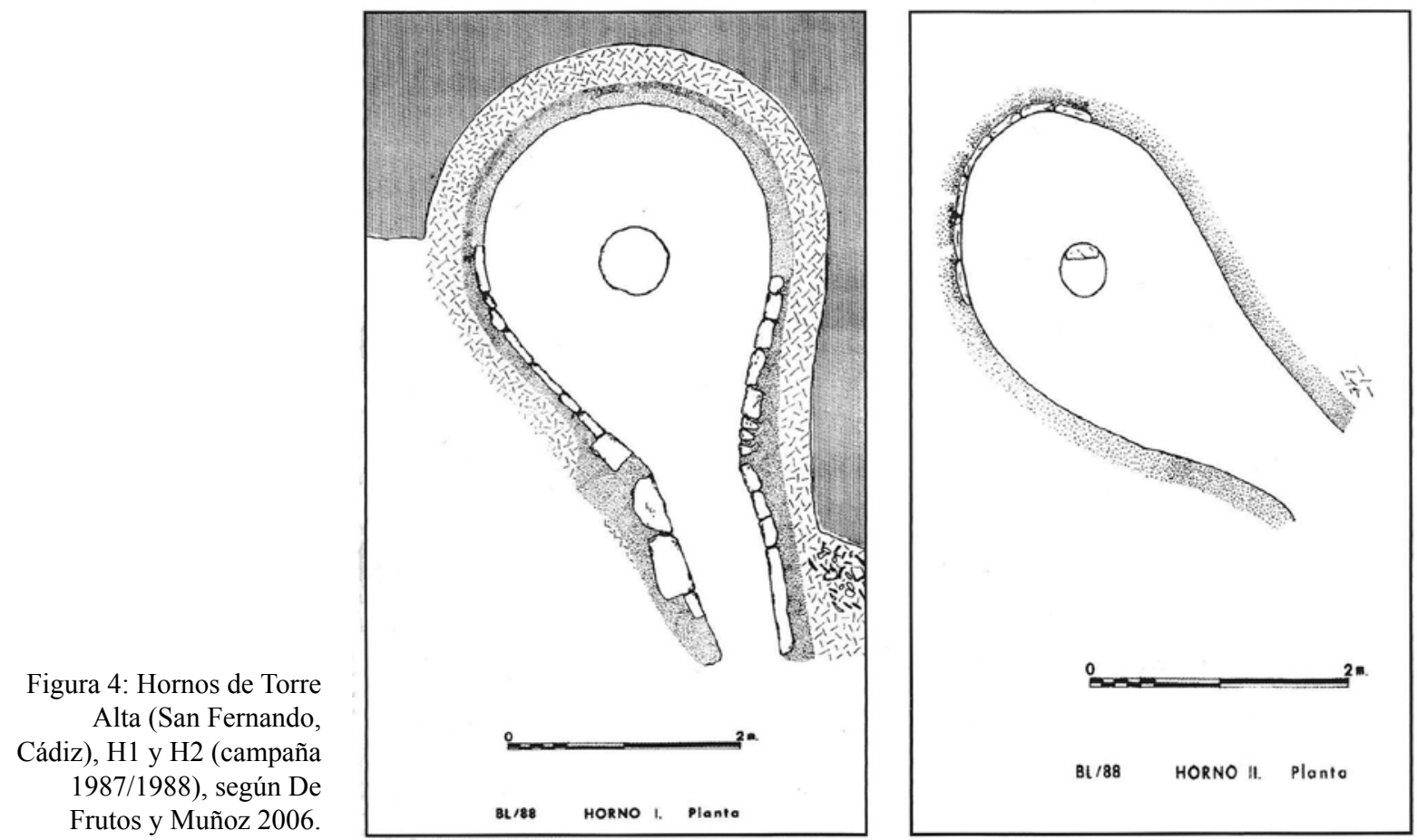

no parecen encontrarse asociadas a niveles de habitación, por lo que en principio no puede hablarse de una reactivación del antiguo centro fenicio sino de una actividad puntual (Aubet y otros 1999: 128). En concreto, se pudo excavar un horno circular de gran tamaño $(5 \mathrm{~m}$. de anchura total) del que sólo se ha conservado parte de la cámara de combustión y de la columna central, así como la huella de un posible pasillo o corredor de acceso (fig. 3). Con objeto de poder soportar el peso de la parrilla, que debió haber alcanzado los 3,20 m. de diámetro, se reforzaron las paredes del horno con un muro de mampostería irregular de 1,20 m. de espesor. Tanto el muro como la columna central estaban a su vez revestidos con ladrillos rectangulares de adobe, endurecidos y parcialmente vitrificados por la acción del calor. Los materiales hallados en el interior del horno -ánforas principalmente, pero también recipientes de almacenamiento y servicio- permiten fechar su actividad a inicios del siglo V a.C. (ibídem: 79-80).

Sin embargo, aunque bastante posterior en el tiempo, es el alfar de Torre Alta (San Fernando) el que se ha convertido en un referente paradigmático de las estructuras de producción de época púnica (Sáez 2011: 64). Las primeras evidencias corresponden a los trabajos realizados entre 1987 y 1988, cuando fueron excavados dos hornos de similares características formales y constructivas, aunque de diferente tamaño (De Frutos y Muñoz 1994). Presentan forma de U, con los extremos cerrados, conformando un largo corredor de acceso (fig. 4). En el interior, una columna central de tambores circulares de mampostería unidos con arcilla y revocados con barro sostenía una parrilla circular, que apareció en ambos casos desplomada en la cámara de combustión. Esta última se encontraba, como viene siendo habitual, excavada en el suelo y recubierta con un muro de tapial reforzado con adobes rectangulares, piedras y ladrillos de adobe colocados verticalmente en la mitad superior de gran parte de su perímetro. El Horno 1 conserva además, en la parte frontal del corredor, el arranque de uno de los arcos que formaban la estructura que sostendría la parrilla: una falsa bóveda realizada con ladrillos plano-convexos unidos con argamasa de arcilla. Como en el caso del alfar de Camposoto, la asociación de un horno de mayores dimensiones a otro más pequeño podía estar relacionado con la producción de dos clases cerámicas distintas: ánforas y grandes recipientes de almacenamiento el primero, y vajilla doméstica el segundo, como se desprende de los materiales encontrados en este contexto (ibídem: 398 ss.). Estos están compuestos fundamentalmente por ánforas de distintos tipos (T-12.1.1.0, T-8.2.1.1, T-9.1.1.1, T-7.4.3.0 e imitaciones de Grecoitálicas antiguas/clásicas), así como por cerámicas comunes (cuencos, platos, lebrillos, ollas de cocina, tapaderas, etc.) que sitúan el funcionamiento de 


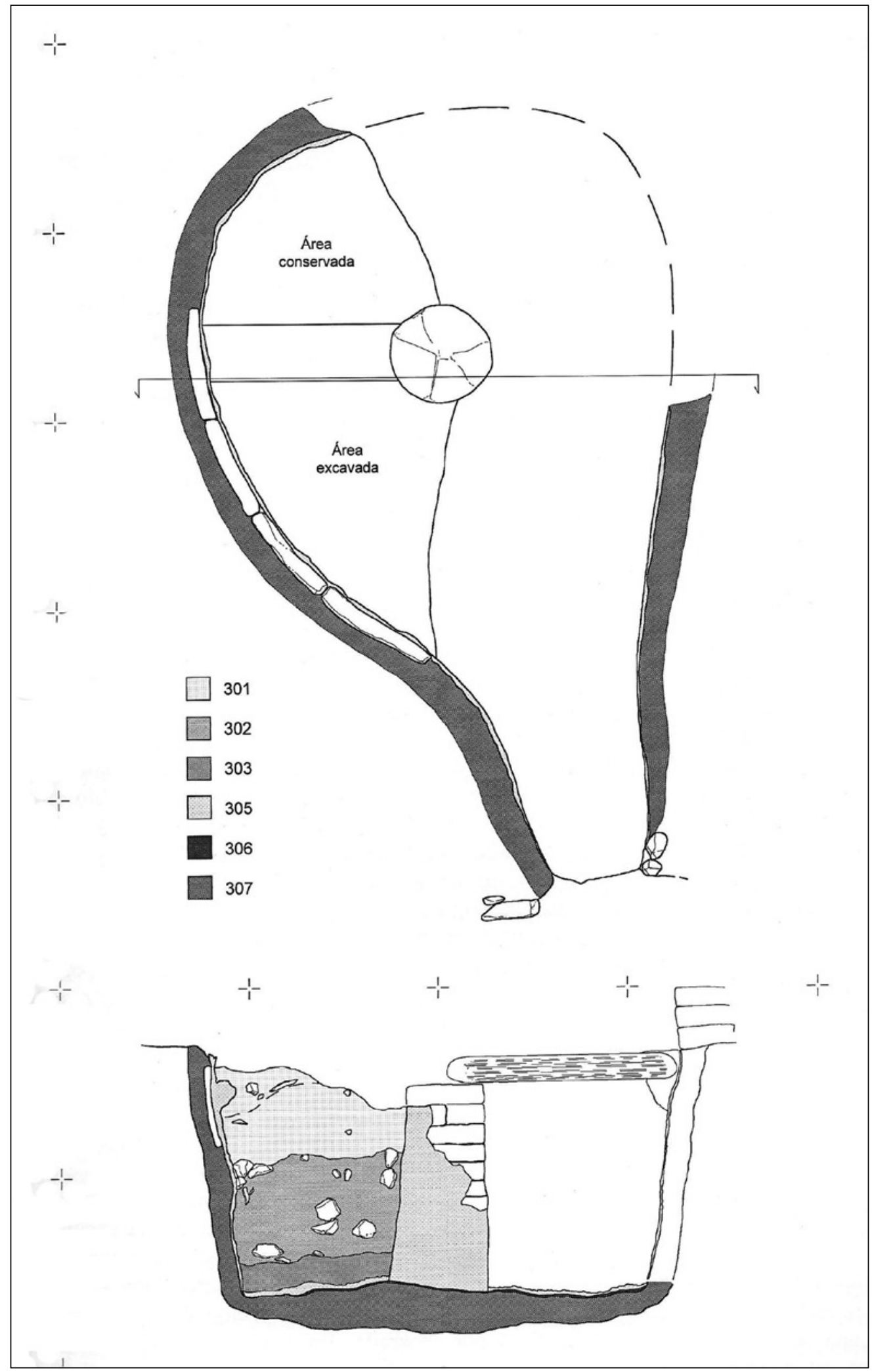

Figura 5: Hornos de Torre Alta (San Fernando, Cádiz), H3 (campaña 2002/2003), según Sáez 2008. 
los hornos en los siglos III y II a.C. No obstante, el hallazgo en campañas posteriores de materiales superficiales de cronología más arcaica apuntan a la existencia de una fase previa, aún inédita, entre los siglos V y IV a.C. (Sáez 2004: 708).

Entre los años 2002 y 2003 esta zona volvió a ser objeto de excavaciones arqueológicas dentro de las tareas de puesta en valor del yacimiento. Gracias a ellas pudieron documentarse tres hornos más, dos escombreras y otras evidencias que han permitido definir con mayor certidumbre la organización de estas estructuras y sus fases de funcionamiento, así como algunos detalles constructivos que contribuyen a la comprensión de aspectos clave en la evolución tecnológica de los hornos cerámicos en los momentos finales del periodo púnico (Sáez 2004; 2008). Los tres ejemplares presentan características similares a los descubiertos en la campaña de 1987/1988, aunque con algunos matices. El Horno 4, por ejemplo, muestra ciertos síntomas de arcaísmo, como su gran tamaño o la forma de la columna central (triangular con los vértices redondeados), así como su disposición con respecto a la fosa de la escombrera situada justo en la entrada del corredor de acceso, que han llevado a sus excavadores a ponerlo en relación con los hornos documentados en el alfar del Sector III de Camposoto y a situarlo en un momento intermedio entre las tendencias de época púnica plena (siglos V-IV a.C.) y las innovaciones propias del siglo III a.C. Estas innovaciones se materializan de forma paradigmática en el Horno 3 (fig. 5). Aunque las dimensiones, la técnica constructiva y la cronología resultan muy similares a las del Horno 1, la existencia de un pequeño testigo del arco de arranque de la parrilla y, sobre todo, el hallazgo in situ de hasta cuatro ladrillos de adobe plano-convexos dispuestos radialmente y desplomados sobre el último nivel de cenizas de la cámara de combustión -debido a la caída de la bóveda del horno sobre el laboratorium una vez abandonado-, evidencian la introducción de un sistema de sustentación de la parrilla hasta ahora inédito en la Península Ibérica, a excepción del caso de Pajar de Artillo (Santiponce, Sevilla), que se tratará posteriormente, y que se ha puesto en relación con soluciones derivadas de los hornos centromediterráneos, como los de Mozia (Sáez y otros 2004: 222). La tercera estructura (Horno 5) constituye la unidad productiva más reciente de todo taller, sirviendo de ejemplo para conocer la evolución tipológica de los hornos cerámicos gadiritas entre los últimos años del siglo III y las primeras décadas del II a.C. Similar a los excavados en 1997 en la cercana Avda. de Al-Andalus, este horno se caracteriza por una reducción de sus dimensiones, el mantenimiento de una proporcionalidad en sus paredes y diámetro, y la introducción del praefurium como novedad técnica, que supone la construcción de un corredor más alargado, dispuesto a un nivel inferior del resto de la cámara de combustión con el fin de llevar a cabo aquí la quema del combustible. No obstante, la parrilla seguiría sustentándose aún sobre barras de adobe plano-convexas dispuestas radialmente sobre los bordes del horno y el pilar central.

Estas últimas excavaciones han venido a demostrar que tanto la definición de los tipos elaborados en el taller como la sucesión de sus fases productivas son más complejas de lo que los datos iniciales habían mostrado (Sáez 2004: 706). Las cerámicas comunes y de cocina (platos, cuencos, urnas, vasos, lebrillos, morteros, jarras, ollas, cazuelas...) están presentes en todos los niveles, por lo que son las ánforas y sus distintas variantes las que una vez más proporcionan las pautas para ahondar en la cronología y evolución del alfar. El elenco de tipos es análogo al hallado en los hornos 1 y 2 , si bien su distribución ha permitido definir hasta cinco fases que se extienden desde mediados del siglo III hasta inicios del último tercio del siglo II a.C. -si tenemos en cuenta las estructuras exhumadas en la Avda. de AlÁndalus-, aunque el momento de máxima producción debe situarse durante la presencia bárcida y sobre todo en los años de la II Guerra Púnica (ibídem: 708-709).

\section{EL HORNO DE PILAR CENTRAL EN EL VALLE DEL GUADALQUIVIR DURANTE LA II EDAD DEL HIERRO Y LOS INICIOS DE LA PRESENCIA ROMANA}

Hasta el momento se han documentado en el Bajo Guadalquivir cuatro centros alfareros de cronología prerromana y romano-republicana: Cerro Macareno, con tres hornos; Carmona, donde se han identificado hasta ocho estructuras de combustión en la zona del Albollón, a los que hay que unir los registrados en la zona de la Puerta de Sevilla, ya de época tardorrepublicana; Itálica, con el horno de Pajar de Artillo, en muy buen estado de conservación; y Sevilla, donde se identificaron hace algunos años dos posibles hornos en las excavaciones realizadas en los sótanos del Palacio Arzobispal.

Las estructuras fornáceas más antiguas dadas a conocer hasta el momento fueron las excavadas a mediados de los años 70 en Cerro Macareno (La Rinconada, Sevilla), correspondiente a los cortes G, F (Fernández Gómez y otros 1979) y H.I, H.II (Ruiz Mata y Córdoba 1999). En los primeros apareció la base de un horno 


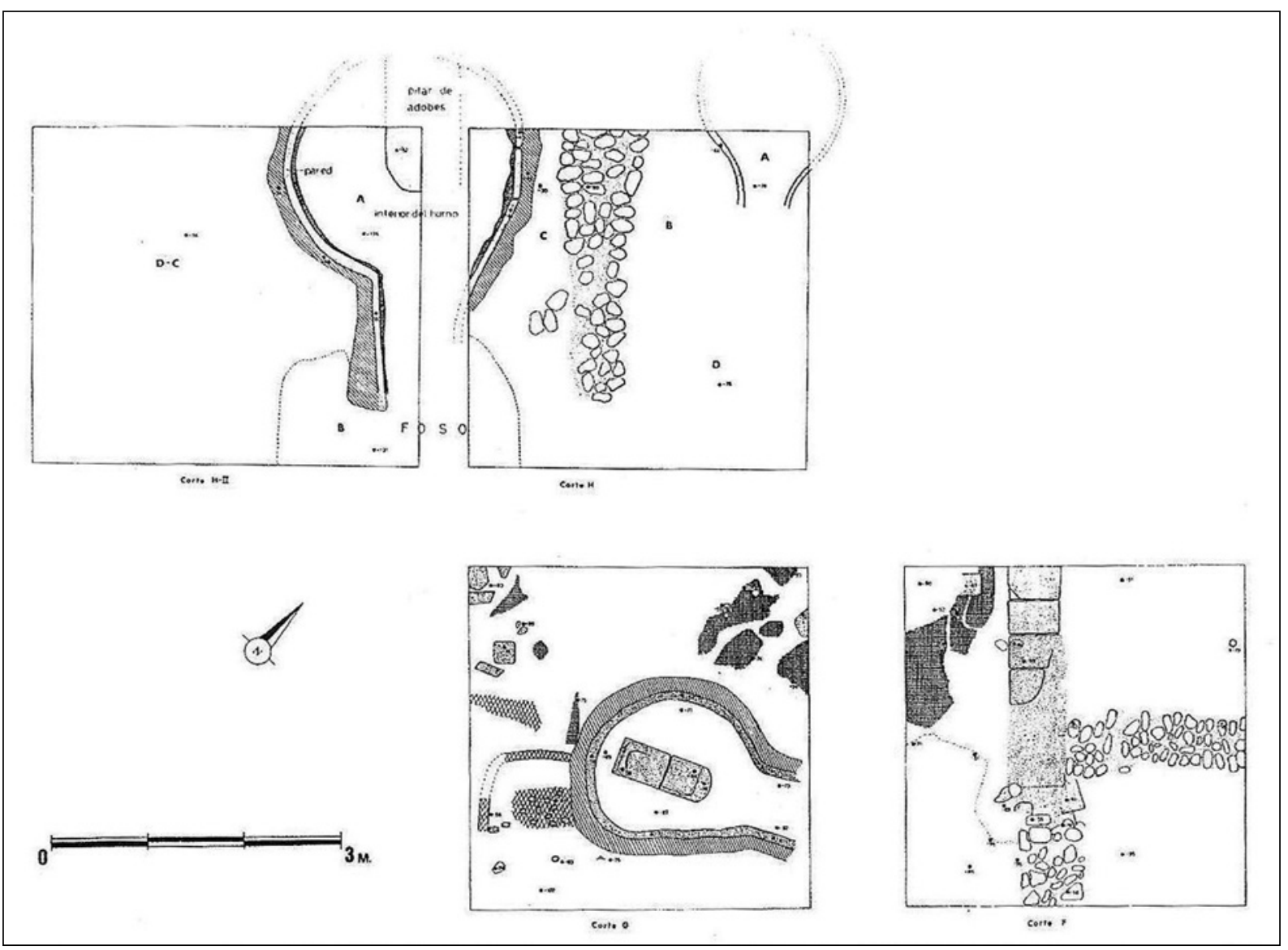

Figura 6: Hornos de Cerro Macareno (La Rinconada, Sevilla), según Ruiz Mata y Córdoba 1999.

de planta ovalada irregular y pilar central con la boca abierta hacia el este (fig. 6). Las paredes estaban construidas con adobes de gran tamaño colocados de forma vertical y revestidos al exterior por una gruesa capa de arcilla endurecida; mientras que el interior se encontraba revocado con una capa de barro, calcinada por la acción del fuego. El pilar central, del que sólo se conserva una hilada de adobes, es de forma rectangular y presenta el extremo que mira hacia la entrada del horno redondeado, probablemente con el fin de facilitar el acceso y la carga de la cámara de combustión. La base del horno es plana, aunque inclinada visiblemente hacia la boca. Junto a él se documentaron muy parcialmente los restos de un edificio de planta rectangular y buena factura, compartimentado al interior con un tabique, que pudo estar relacionado con las instalaciones del alfar, si bien no se encontraron elementos que permitieran definir una función clara. De hecho, el espacio exterior al muro de cierre de este edificio está ocupado por dos hoyos rellenos de cenizas, restos de adobe y material cerámico, orientados respectivamente a las bocas de los hornos exhumados en el corte $\mathrm{G}$ y en el contiguo corte H. Se trata, según los excavadores, de desechos del propio alfar, ya que además de fragmentos de ánforas y cerámica común de pastas locales, en el primero de ellos aparecieron adobes similares a los utilizados en las paredes y la parrilla de estas estructuras.

Los cortes H.I y H.II proporcionaron dos estructuras fornáceas de similares características, aunque sólo pudieron documentarse parcialmente (fig. 6). El horno mejor conservado, que es además el de mayores dimensiones, presentaba también una planta ovalada irregular y un pilar central rectangular, con la parte delantera redondeada, si bien en este caso su boca estaba orientada al sureste. Frente a ella se extiende igualmente una especie de foso destinado con probabilidad a las tareas de limpieza y carga. Por lo que respecta a su cronología, tanto los restos de producción, principalmente ánforas locales de los tipos $\mathrm{B}$ y $\mathrm{C}$ de Pellicer y cerámicas comunes (cuentos, urnas, lebrillos), como la vajilla importada, 


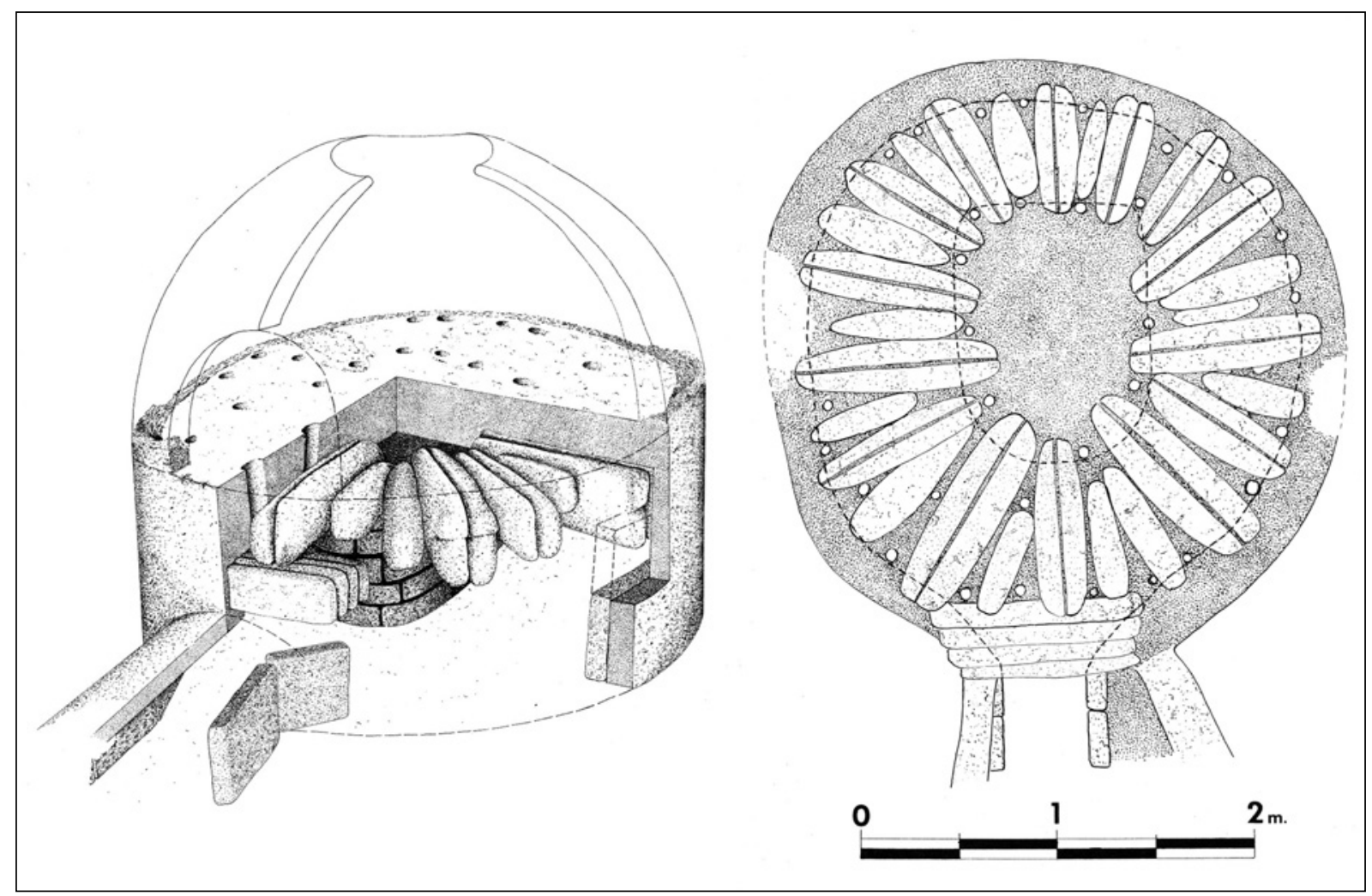

Figura 7: Horno de Pajar de Artillo, Itálica (Santiponce, Sevilla), a partir de Luzón 1973.

representada por dos copas "tipo Cástulo" (corte H.I y H.II) y una lucerna de barniz negro griega (corte G), nos sitúa verosímilmente entre finales del siglo $\mathrm{V}$ y mediados del IV a.C. Una fecha que viene confirmada también por los materiales hallados en los niveles subyacentes, en ningún caso posteriores al siglo $\mathrm{V}$ a.C.

El horno de Itálica, además de mantenerse en muy buen estado, presenta una serie de características constructivas que lo convierten en un ejemplar especialmente singular (Luzón 1973: 16-25). Su planta es circular, de 2'60 m. de diámetro, con la boca orientada hacia el este, precedida por un praefurnium cubierto por una pequeña bóveda de adobe (fig. 7). Se conserva tanto la cámara de combustión como la parrilla y el arranque de la cámara de cocción, de la que quedan apenas $20 \mathrm{~cm}$. de alzado. Para su construcción se excavó un foso de $3 \mathrm{~m}$. de diámetro y 0'95 m. de profundidad, que posteriormente se recubrió completamente de barro. Las paredes del horno están realizadas con ladrillos de adobe colocados en vertical, mientras que los del pilar central se han situado horizontalmente, formando un cuadrado cuya parte anterior ha sido labrada de forma convexa, como acabamos de ver también en los ejemplares de Cerro Macareno. El elemento más singular es el sistema de sustentación de la parrilla, constituido por una estructura de barras de adobe plano-convexas colocadas de canto radialmente entre el pilar central y la pared exterior del horno. Estas barras van dispuestas generalmente por pares, unidas por la cara plana y alternadas con otras piezas de menor tamaño que se encajaron como cuñas en los huecos. Una vez finalizada, la estructura se cubrió con un piso horizontal de barro al que previamente se habían insertado una serie de estacas de madera con objeto de dejar los huecos necesarios para la transmisión del calor y los gases de la cámara de combustión hacia la de cocción. $\mathrm{Su}$ distribución grosso modo aprovechaba los espacios dejados por el sistema de sustentación. De la cámara de cocción, por su parte, poco se puede decir, aunque su excavador trató de proponer una reconstrucción hipotética a partir de distintas representaciones de hornos y de otros ejemplares de similares características conservados en diversos lugares del Mediterráneo (fig. 7).

Asociado a esta estructura aparecieron abundantes fragmentos de cerámica con fallos de cocción (especialmente ánforas del tipo $\mathrm{D}$ de Pellicer y recipientes 


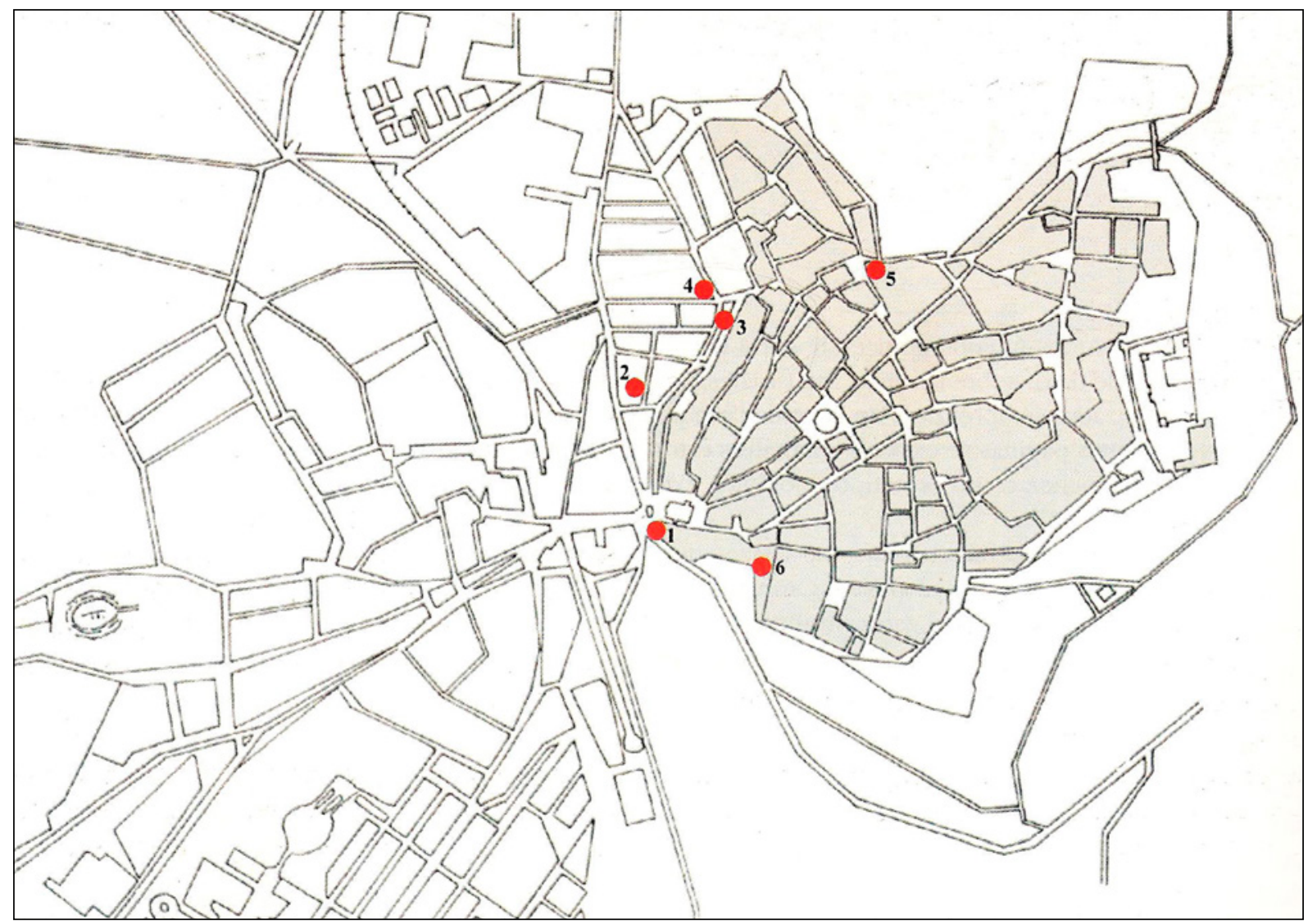

Figura 8: Estructuras alfareras documentadas en el núcleo urbano de Carmona, según Rodríguez 2001: 1. Cenicero; 2. c/ Montánchez nº 4; 3. c/ González Parejo no 10; 4. c/ Dr. Fleming nº 25; 5. Albollón; 6. c/ Arellano no 2.

comunes pintados), así como algunos birlos de barro utilizados con toda probabilidad para separar las piezas dentro del horno. Luzón fechó su actividad en la segunda mitad o finales del siglo II a.C. (Luzón 1973: 25), mientras que revisiones posteriores han elevado esta cronología hasta el siglo III (Pellicer 1998: 153-155) o incluso finales del IV a.C. (Ruiz Mata 1998: 218); no obstante, un examen de los materiales, sobre todo teniendo en cuenta los contextos asociados a los niveles de ocupación anteriores e inmediatamente posteriores, permiten situarlo en los momentos finales del siglo III e incluso a inicios del II a.C.

En Carmona encontramos dos áreas industriales más o menos diferenciadas topográfica y cronológicamente dentro de la inmediata periferia urbana (fig. 8). La primera se establece al norte, junto a la vaguada formada por el arroyo Albollón, y se remonta al periodo turdetano; mientras que la segunda se extiende hacia el oeste, cerca del Postigo y de la muralla de la Barbacana, y al norte de la Puerta de Sevilla. Aquí se han documentado varias estructuras fornáceas en las calles Dr. Fleming 25, Montánchez 4 y González Parejo 10 (Rodríguez 2001), y más recientemente en la calle Dr. Fleming 13-15 (Ortiz y Conlin, e.p.), cuya cronología nos sitúa ya en torno al cambio de era.

En la zona del Albollón se excavaron en 1990 ocho hornos de planta circular y tamaño variable (Rodríguez 2001: 311-312). Siete de ellos presentaban el característico pilar central exento, mientras que en sólo un caso el pilar se había convertido en un muro adosado al fondo de la cámara de combustión. Todos contaban con una parrilla sustentada por una falsa bóveda de adobes, aunque apenas se han podido documentar de forma completa (fig. 9). Las cámaras estaban amortizadas por un relleno en el que abundaban tanto los recipientes comunes de mesa y almacenamiento (lebrillos sobre todo), como las ánforas, especialmente los tipos BC de Pellicer y 8.2.1.1 de Ramón (Belén 2006: 240), lo que nos ofrece un amplio arco cronológico para la actividad de este sector que se extiende desde 

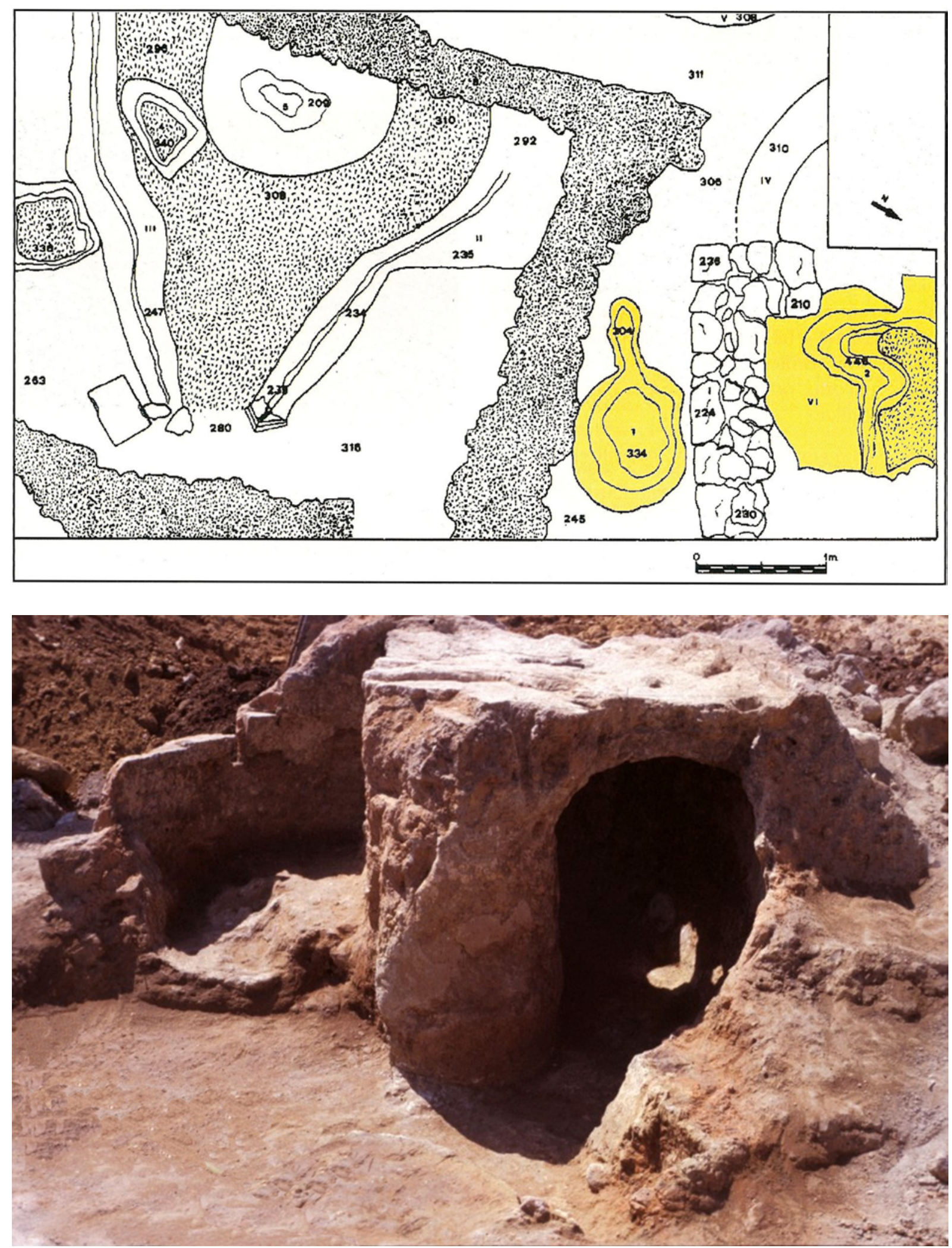

Figura 9: Hornos del área artesanal del Albollón (Carmona, Sevilla), a partir de Rodríguez 2001.

ISSN: 1133-4525 ISSN-e: 2255-3924

SPAL 21 (2012): 9-38

http://dx.doi.org/10.12795/spal.2012.i21.01 


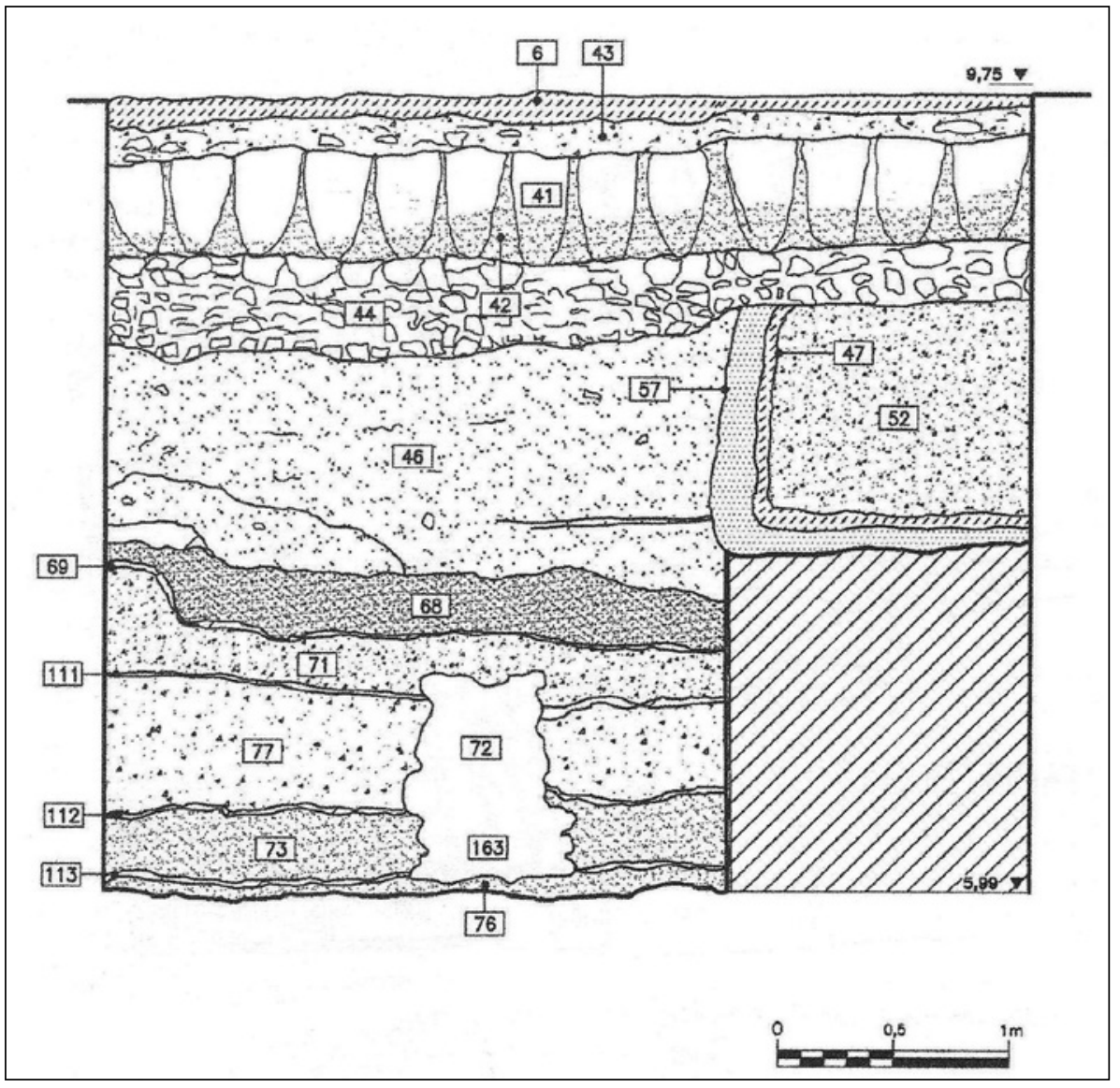

Figura 10: Hornos del Palacio Arzobispal de Sevilla, corte I, según Mora y Romo 2006. el siglo IV hasta avanzado el siglo II a.C. No obstante, a la espera de una publicación detallada de los resultados de la excavación y de sus repertorios materiales, los análisis de pasta efectuados sobre varios ejemplares de distintas clases cerámicas y su comparación con las muestras de barros obtenidas en algunas canteras tradicionales situadas en los alrededores de Carmona, han confirmado el origen local de estas producciones (Rodríguez 2001: 312-313).

Por último, las excavaciones llevadas a cabo en el año 2003 en los sótanos del Palacio Arzobispal de Sevilla han permitido documentar dos hornos que podrían pertenecer al sector portuario e industrial de la primitiva Spal, situado extramuros del oppidum, junto a un antiguo codo formado por el río Guadalquivir (González Acuña 2011: 438; Escacena y García Fernández, e.p.). En la primera campaña, la única publicada hasta el momento, se efectuaron tres sondeos en el espacio ocupado por el antiguo Archivo, así como un control general de los movimientos de tierra (Mora y Romo 2006).
En el ángulo SE del Corte I se registraron parcialmente los restos de la cámara de combustión de un horno de planta circular, cuyo diámetro se calculó en unos 2,60 m. aproximadamente, con una profundidad mínima de 1,10 m. (fig. 10). Las paredes y el suelo, excavados sobre los niveles de ocupación anteriores, estaban revestidos de arcilla y revocados al interior con un enlucido de cal de $5 \mathrm{~cm}$. de grosor. Debido a su ubicación y a su lamentable estado de conservación no pudo documentarse el sistema de sustentación del laboratorium que, dado su tamaño, hubo de situarse también sobre un pilar o columna central. El interior de la cámara estaba colmatado por un relleno de color oscuro con abundantes cerámicas y desechos de producción. Aquí encontramos un ejemplar tardío del ánfora MPA4 (T-12.1.1.1/2) y dos bordes de la forma Pellicer D, así como un cuenco de cerámica "tipo Kouass", correspondiente a la forma IX-A de Niveau, y algunos fragmentos de ánforas de tipo indeterminado con fallos de cocción. Estos materiales aparecen asociados al cuello de un ánfora Dressel 1 y a una pátera de cerámica 
Figura 11: Hornos del Palacio Arzobispal de Sevilla, corte IV, según Mora y Romo 2006.

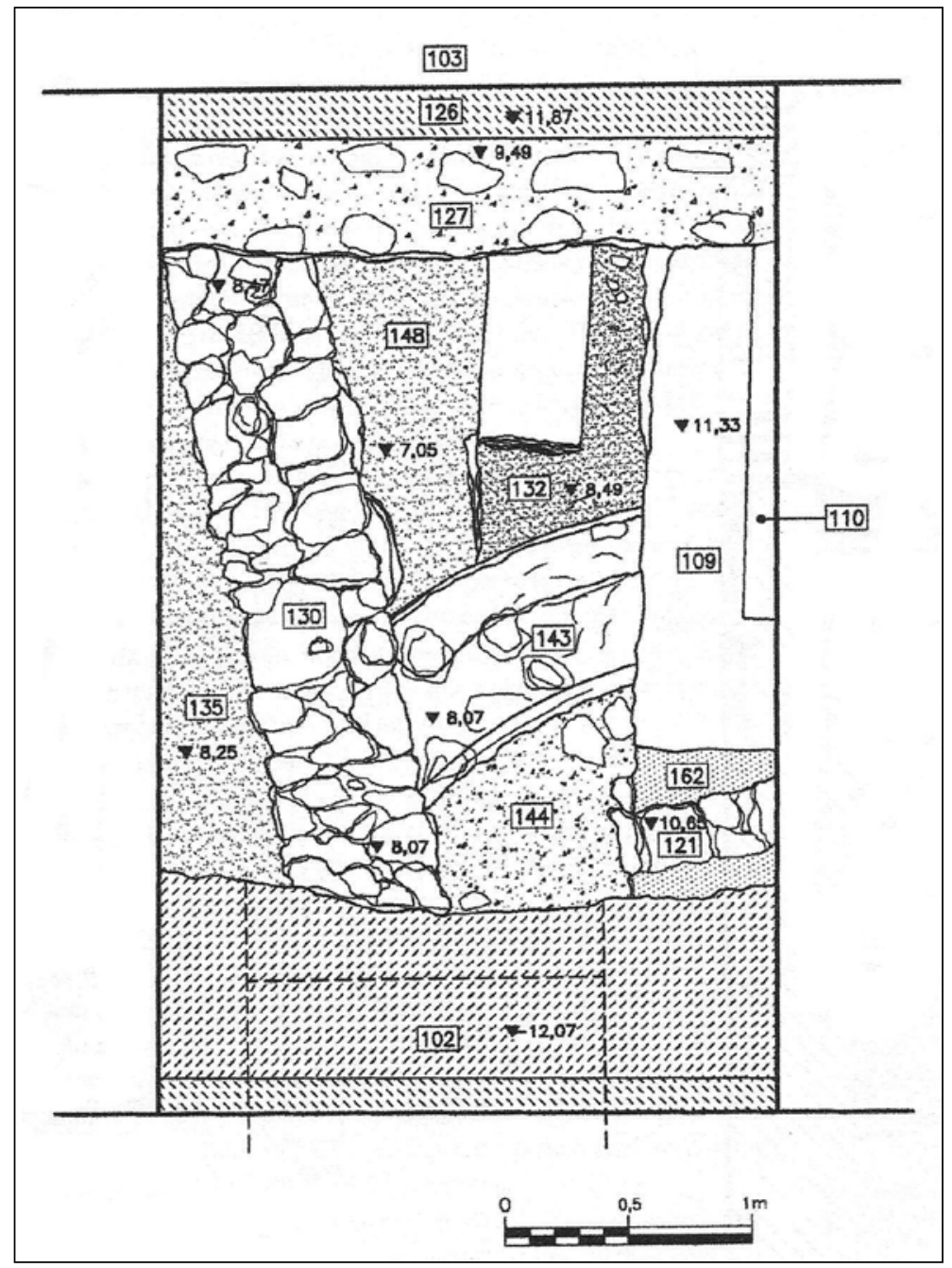

campaniense $\mathrm{B}$, que proporcionan una fecha post quam de inicios del siglo I a.C. Como se ha dicho, este horno está excavado, a su vez, sobre un relleno de tierra de $1,30 \mathrm{~m}$. de potencia en el que se registraron tres bordes del tipo Pellicer D, varias asas pertenecientes a contenedores púnicos (T-8.2.1.1 o T-9.1.1.1), así como el arranque de asa de un ánfora ibicenca de tipo indeterminado que podemos fechar grosso modo en torno al siglo II a.C. (García y Ferrer 2010: 353).

El segundo de los hornos apareció en el Corte IV, bajo un muro de calcarenita con el que guarda una compleja relación estratigráfica (fig. 11). Al igual que el anterior, sólo se ha podido documentar muy parcialmente en una superficie de poco más de $1 \mathrm{~m}^{2}$. Se trata de un muro de tendencia circular de $2,65 \mathrm{~m}$. de radio y $85 \mathrm{~cm}$. de recorrido, con una anchura de entre 80 y $50 \mathrm{~cm}$. realizado con pellas de adobe y fragmentos cerámicos. Correspondería a la cámara de cocción, cuya huella quedó registrada en el perfil norte entre las cotas 9'03 / 7'85, punto en que se detuvo la excavación. Por su parte, la cámara de combustión y la parrilla, situadas a una cota inferior, no han podido ser registradas, como tampoco el sistema de sustentación, embutido con probabilidad dentro del perfil. Entre el material recuperado de las paredes del horno se hallaron fragmentos de al menos tres ánforas T-8.2.1.1, así como un pie anular perteneciente a un mortero de tradición púnica, lo que permite fechar su construcción en torno al siglo II a.C. Ni el relleno de la cámara de cocción ni los depósitos que se asocian a esta estructura hacia el exterior ofrecieron restos representativos, debido en gran medida a la alteración provocada por las fases edilicias posteriores (García y Ferrer 2010: 355-357). 
A pesar de las limitaciones antedichas y del estado de conservación de las estructuras exhumadas, tanto los materiales vinculados a sus niveles de construcción y amortización como las cotas de uso y su ubicación, permiten interpretar estas instalaciones como un alfar suburbano, cuyo funcionamiento cabría situar entre el siglo II e inicios del I a.C.

\section{EL HORNO DE PILAR CENTRAL EN EL VALLE DEL GUADALQUIVIR DURANTE EL ALTO IMPERIO}

Los hornos cerámicos romanos de Carmona constituyen el "eslabón" de enlace entre las estructuras fornáceas turdetanas y las imperiales en la región. Por ahora, sólo un pequeño horno del yacimiento de Cobre las Cruces (Gerena, Sevilla) acompaña a los carmoneneses en esta época tan escasamente documentada de la producción cerámica del Bajo Guadalquivir (García Vargas y Chic García 2004:307), tratándose de una estructura de cámara circular y pilar central realizada en adobes y en la que se cocieron fundamentalmente materiales de construcción. Aparentemente, ni la morfología de los hornos, ni la técnica constructiva de los mismos, ni los detalles técnicos de su funcionamiento se vieron grandemente alterados en estos primeros momentos, aunque el repertorio formal cerámico si experimentó una importante, aunque no radical, transformación. En virtud de la misma, las alfarerías añaden a partir del siglo I a.C. cerámica común y ánforas con morfologías derivadas de la tradición artesanal itálica a su elenco cerámico tradicional (evolucionado).

El área occidental extramuros de Carmona (supra), un sector artesanal que se desarrolló a partir del último tercio del siglo I a.C. y que se encuentra relativamente alejado del "barrio alfarero" del Albollón, aún activo en el siglo II a.C., presenta hornos en todo homologables a los tardo-turdetanos de éste última zona (fig. 8). En el solar de la calle Montánchez 4 (Cardenete y otros 1989) se excavó una estructura de 3,20 m. de diámetro con pilar central de planta oval y el trasdós de la parrilla abovedado, aparentemente mediante aproximación de las hiladas de adobes (fig. 12). Esta solución arquitectónica es en todo homologable a la que presenta el horno $n^{\circ} 3$ del Albollón, del siglo II a.C. (Rodríguez 2001), aunque la tipología no es exactamente la misma, pues éste último presenta el pilar unido a la pared del fondo del horno, con lo que se delinea una especie de murete medial, característica tipológica que tiene sus paralelos más cercanos, como se ha visto, en la bahía de
Cádiz. Pero aparte de este detalle formal, puede decirse que las soluciones abovedadas para el trasdós de la parrilla en la Carmona de los siglos II y I a.C. preludian el empleo masivo desde época julio-claudia de arcadas complejas como sistema generalizado de sustentación en los hornos de pilar central. Pensamos que se trata de un recurso para ganar espacio en la cámara inferior o cámara de combustión, mejorando el rendimiento calórico y permitiendo construir estructuras de dimensiones mucho mayores, apropiadas, por tanto, para un momento de incremento notable de las necesidades de abastecimiento de vajillas cerámicas.

Los materiales publicados de Montánchez 4 (Rodríguez 2001: 316, fig. 9) muestran un panorama tipológico (ánforas Haltern 70 "iniciales" y “clásicas”: García Vargas y otros e.p.; "orzas" con dos asas, lebrillos de cuello estrangulado y borde almendrado, jarras con asas con apéndices superiores...) que puede situarse en época temprano y medio-augustea (30-10 a.C.), y corresponde a un contexto arqueológico que se interpreta como la última tanda de recipientes fabricada en el horno, ya que los materiales aparecen sobre restos de combustión de acebuche (Rodríguez 2001: 317). En cualquier caso, estos materiales cerámicos marcan la fecha ante quam para el funcionamiento de la piroestructura, lo que indica que en época augustea se ha mantenido y consolidado el tipo de horno tradicional en la región, el de cámara circular con pilar central, que será "adoptado" por la industria alfarera romana con transformaciones arquitectónicas menores. Estas transformaciones marcarán lo que podríamos llamar un primer "horizonte romano imperial" en la tecnología de construcción y funcionamiento de las estructuras fornáceas regionales.

Este "primer horizonte" tecnológico puede rastrearse en un buen número de talleres rurales a lo largo de los siglos I al III d.C., un amplio período de tiempo en el que estas estructuras de pilar central y gran cámara circular son ubicuas en las alfarerías del valle del Guadalquivir y del Genil, seguidas muy de lejos por otras claramente minoritarias (Cf. García Vargas 1993; Chic García y García Vargas 2004). Desde muy pronto, parece haberse impuesto el sistema de sustentación de la parrilla basada en un sistema de arcos abiertos en palmera que descansan en el pilar central y en las paredes de la cámara, bien directamente bien mediante salmeres, sin perjuicio de que, en ocasiones, sólo uno de cada dos arcos llegue realmente a descansar en el pilar central, haciéndolo los arcos alternos en el punto en que confluían con los laterales a ellos.

El enorme peso que soportaba la parrilla, cargada con una hornada de 30 a 50 ánforas de hasta 25 kilos 


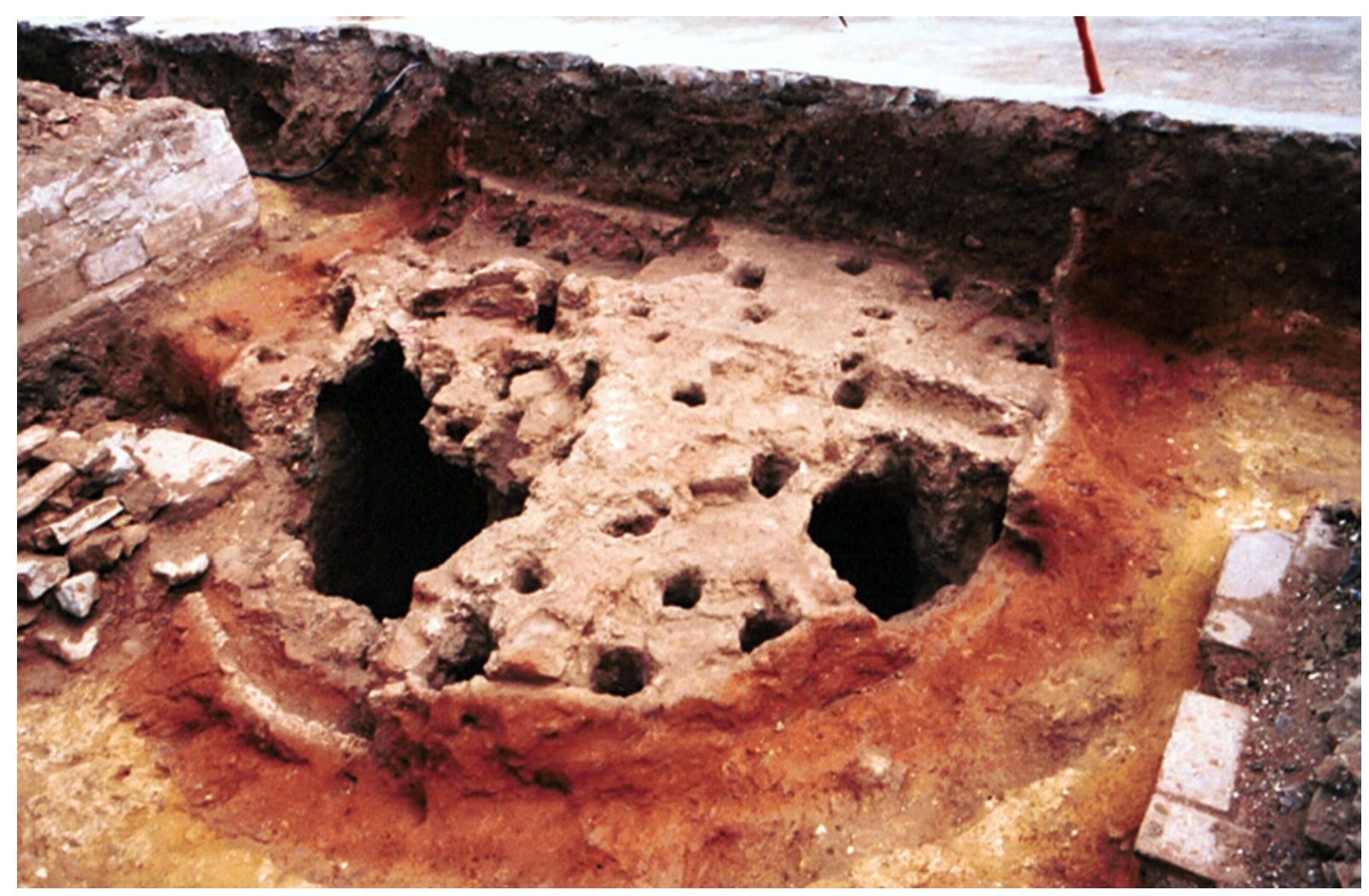

Figura 12: Horno del alfar de c/ Montánchez nº 4 (Carmona, Sevilla)

de peso cada una, precisaba de un pilar sólido y con la anchura suficiente para recibir un gran número de arcos. En algún caso, el pilar central llego a alcanzar los $3 \mathrm{~m}$. de diámetro, aunque lo habitual es que sus dimensiones estuvieran entre los 1,40 y los $2 \mathrm{~m}$. de diámetro máximo, en el interior de una cámara que oscilaba entre los 4,80 y los $5 \mathrm{~m}$. de diámetro. Esto dejaba poco espacio practicable dentro de la cámara de combustión y, lo que es más importante, creaba un espacio central sin orificios en la parrilla (el correspondiente a la cara inferior de ésta que estaba en contacto con la superficie superior del pilar) que no transmitía adecuadamente el aire caliente a la cámara de cocción, dando lugar a diferencias importantes de temperatura entre las diversas zonas del laboratorium. La solución habitual era perforar el pilar con una serie de toberas que se practicaban sobre la pared lateral del mismo y giraban enseguida en ángulo recto, o bien lo atravesaban en diagonal. Ambas soluciones pueden comparecer en los mismos alfares, como es el caso del Castillo de Azanaque (Romo y Vargas 2001: 407) (fig. 13). Simultáneamente, se practicaban a veces perforaciones en las paredes perimetrales del horno que, funcionando como toberas, conducían el calor al piso superior en los límites del mismo, añadiendo de este modo una zona de calor ascendente en el interior de los muros y contribuyendo a aumentar la superficie activa de la estructura de cocción. Este procedimiento técnico se encuentra representado en el horno de La Catria, en Lora del Río (Remesal 1977-78). Llama la atención, dada las enormes dimensiones de la mayoría de los hornos excavados de pilar central, que en ellos los praefurnia suelan ser cortos, pero el gran tamaño de la cámara de combustión precisa de la cercanía de la llama para alcanzar la temperatura necesaria y para efectuar correctamente el tiro, lo que se soluciona con un praefurnium de poco recorrido que sitúe el fuego muy cercano al acceso de la cámara de combustión del horno.

Puede decirse, pues, en visto de lo expresado hasta ahora, que los hornos de los alfares del Guadalquivir y del Genil han conservado a lo largo de la época altoimperial la tradición artesanal prerromana, con estructuras tipológicamente adscribibles a la forma Ia de Cuomo di Caprio (2007): cámara circular con pilar central. Pero también que esta tradición local sufrió una serie de modificaciones importantes a lo largo 
del tiempo, dando lugar a una realidad artesanal mucho más compleja y dinámica que no se agota en el mayor tamaño y complejidad técnica de las estructuras furnáceas, sino que alcanza igualmente a la localización espacial de los talleres, con una visibilidad especial del artesanado rural, y a la organización y colocación de los hornos en el interior de la alfarería. A partir del siglo I d.C. son frecuentes, por ejemplo, las baterías de hornos con un muro de fachada común (Romo y Vargas 2001), o las estructuras arquitectónicas con espacio abierto frontal que engloban varios hornos o los corredores y pasillos de servicio para entretener y servir a más de una estructura de cocción (Tabales 2003). Todo ello indica una organización más racional de los alfares como consecuencia, seguramente, de una producción masiva (fig. 14).

\section{CONCLUSIONES}

La aparición de los hornos de tiro vertical y, en general, la expansión de la alfarería como actividad artesanal especializada implica y refleja a la vez importantes cambios en la matriz socioeconómica de las poblaciones indígenas de la Península Ibérica, que irán intensificándose a lo largo de la Edad del Hierro. Implica, porque tanto el manejo del horno como el torneado requiere de unos conocimientos y una experiencia que sólo pueden ser adquiridos tras un largo aprendizaje llevado a cabo en los propios talleres; asimismo, las tareas ligadas a la producción alfarera, desde la obtención y tratamiento de la arcilla, o la recolección del combustible, hasta la elaboración y cocción de los recipientes, así como la propia construcción de los hornos, exigen una dedicación temporal completa o casi completa, especialmente en los meses de verano, coincidiendo con el momento en que se desarrollan la mayoría de las actividades agrícolas de los cultivos mediterráneos, que es también el momento de mayor demanda de recipientes cerámicos (Coll 2000: 203). Asistimos, pues, al surgimiento de un nuevo especialista que se irá sumando durante Edad del Hierro a los ya existentes (metalúrgicos principalmente), y a los nuevos grupos de comerciantes, albañiles y otros artesanos, constituyendo un colectivo segregado de la clase productora, pero mantenido con parte de los excedentes obtenidos de ésta.

Por otro lado, refleja un cambio en las estrategias productivas, pasando de un modelo de economía de subsistencia, propio de finales de la Edad del Bronce, con una producción de excedentes muy limitada al autoconsumo y al mantenimiento de algunas funciones básicas en el seno de una sociedad redistributiva (intercambio, producciones especializadas, etc.), a una economía plenamente excedentaria, con una producción especializada orientada al intercambio. Prueba de ello es la fabricación de recipientes anfóricos, destinados exclusivamente al envasado y comercialización de recursos alimenticios. Ésta se inicia en los centros coloniales durante el siglo VIII a.C. para extenderse a partir del VI a.C. por el valle del Guadalquivir y las campiñas interiores, al tiempo que se formalizan nuevas variantes derivadas de los prototipos de origen fenicio (ánforas R-1). Lo mismo ocurre con la cerámica común (sobre todo la destinada al almacenamiento y servicio de mesa), que adopta y sintetiza técnicas, formas y decoraciones de tradición oriental, adaptándose a las necesidades cotidianas (y a los usos singulares) de las poblaciones vernáculas, que irán desplazando paulatinamente a las producciones elaboradas a mano. Así pues, como afirma Coll Conesa, la implantación de estas nuevas estructuras artesanales no indica únicamente un cambio tecnológico, sino la aplicación de la cerámica a la satisfacción de nuevas necesidades sociales, gracias precisamente al aumento en el volumen de fabricación de envases y recipientes a través de una producción estandarizada y seriada (Coll 2000: 202-203).

Como puede comprobarse líneas arriba, es posible seguir la evolución tecnológica y productiva de los hornos de tradición oriental desde su primera implantación en las colonias fenicias de la Península Ibérica hasta su plena adopción por parte de las comunidades locales, donde probablemente el peso de la presencia púnica debió ser también muy notable. Mientras que los primeros ejemplares aún mantenían la tradicional planta bilobulada o en "omega", con el muro axial sosteniendo la parrilla, a partir de finales del siglo VI a.C. éstos serán paulatinamente sustituidos por otros modelos más evolucionados desarrollados a partir de los mismos prototipos, con planta pseudocircular y un pilar central ovoide, primero unido a la pared posterior de la cámara de combustión por un murete de adobe, como se ha visto en el alfar de Camposoto (Ramón y otros 1997), y posteriormente exentos en los siglos V y IV a.C. Este modelo es el que se extiende desde el siglo $\mathrm{V}$ a.C. hacia los alfares del bajo valle del Guadalquivir, dando lugar a variantes de distintos tamaños y soluciones constructivas, generalmente con un pilar de grandes proporciones y forma oval o cuadrangular con las esquinas redondeadas (fig. 6), resultado de un proceso centenario de interacción mutua que conllevó la mejora técnica de los hornos y un incremento en la pericia del artesanado indígena. Las novedades que comienzan a 

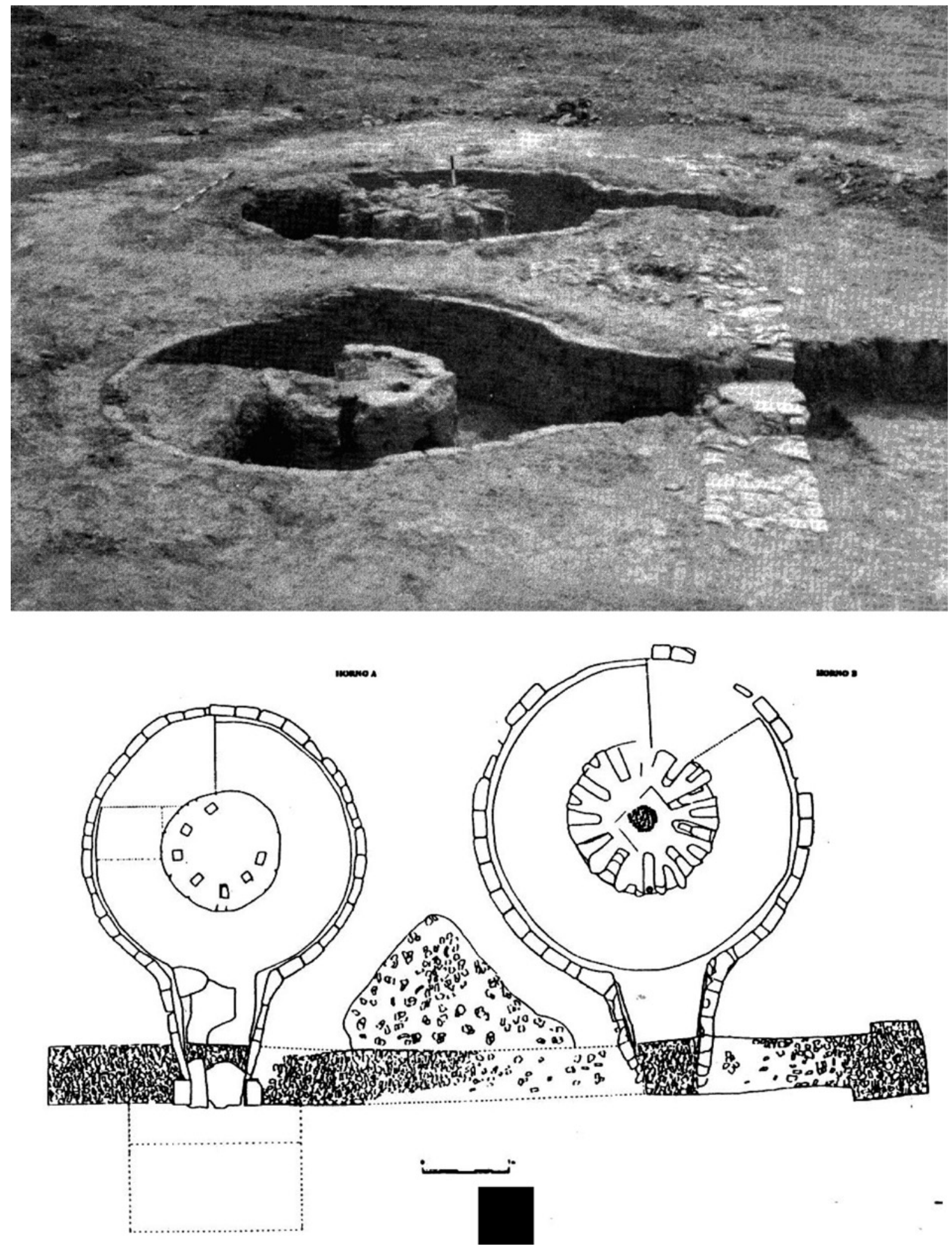

Figura 13: Hornos del alfar de Azanaque (Lora del Río, Sevilla), a partir de Romo y Vargas 2001.

ISSN: 1133-4525 ISSN-e: 2255-3924

SPAL 21 (2012): 9-38

http://dx.doi.org/10.12795/spal.2012.i21.01 
incorporarse a partir del siglo III a.C. en los talleres de la bahía de Cádiz, que se convierten en paradigma de la tradición alfarera fenicio-púnica occidental, se proyectan también sobre los modelos del interior, como puede apreciarse en el ejemplar de Pajar de Artillo, en Itálica (fig. 7). Estas novedades afectan sobre todo al sistema de suspensión de la parrilla y está relacionado no tanto con un aumento en el tamaño y la capacidad productiva de los hornos, como con su facilidad de construcción, mantenimiento y reparación, es decir, con la posibilidad de incrementar su número y el volumen de producción de los talleres dentro de una dinámica comercial más competitiva que coincide precisamente con el inicio de la presencia bárcida en el sur de la Península y el papel económico que adquirirá Gadir en el contexto de la II Guerra Púnica (Sáez 2008: 203).

La introducción de parrillas móviles sustentadas con un sistema de barras de adobe plano-convexas dispuestas radialmente entre el pilar central y la pared del horno es una solución que cabría situar en este momento, coincidiendo con un aumento en la longitud de los corredores de acceso y la aparición en los hornos gadiritas de pilares totalmente circulares, realizados con tortas de adobe prefabricadas (ibídem). No parece casualidad, pues, que estos hornos cuenten con paralelos casi exactos en los prototipos norteafricanos del siglo III a.C., como se desprende del ejemplar documentado en Kerkouan o en los propios talleres metropolitanos de Cartago (Sáez y otros 2004). No obstante, aún contamos con pocas evidencias para poder conocer la verdadera dimensión de estos cambios en la tipología de los hornos, así como de la implementación que se produce en la producción alfarera a finales del siglo III e inicios del II a.C. en el interior de Turdetania. Ignoramos si este fenómeno responde a la introducción de un nuevo modelo artesanal, mediante el traslado directo de alfareros tunecinos, a través de una convivencia y cooperación, o simplemente por difusión tecnológica, aunque lo que está claro es que no es ajeno a otras transformaciones operadas en el tejido productivo, el patrón de asentamiento o las estrategias de explotación del territorio (Sáez 2008: 204), como la extensión de las factorías agrícolas en la campiña de Cádiz y en las márgenes orientales del Lacus Ligustinus.

En cualquier caso, salvo en la evolución de las plantas y en el sistema de sustentación, apenas se observan diferencias importantes en los materiales y en las técnicas constructivas empleadas en los hornos durante la segunda mitad del primer milenio a.C. Ello supone admitir lógicamente un desarrollo de las formas, pero también "una misma tradición artesanal, es decir, una renovación generacional de los alfareros dentro del ámbito local" (Sáez 2008: 201). También hay que prestar atención a la ubicación de los talleres, ya que durante la Edad del Hierro y salvo excepciones -como ocurre con la factoría agrícola de La Campiña de Marmolejo- la alfarería se presenta como una actividad eminentemente urbana, rasgo que se perpetuará durante los primeros siglos de la ocupación romana. Esta cuestión no es baladí, si tenemos en cuenta las connotaciones socio-económicas que ello implica, en relación con la producción y distribución de excedentes agropecuarios, los métodos de envasado y transporte, así como las estructuras de comercialización; y aún es más representativo si atendemos a los cambios que se operan en la industria a partir del principado de Augusto y el traslado de los talleres a los nuevos emplazamientos rurales.

Los hornos romanos del valle del Guadalquivir heredarán sin duda estas raíces locales. Aquí, a pesar de mejoras sustanciales en la construcción de las estructuras de combustión y en la organización del espacio alfarero, la antiquísima morfología de los hornos cerámicos locales se mantuvo un largo tiempo y las "novedades" del artesanado itálico se recibieron de forma tardía y, ciertamente, atenuada. De hecho, no se puede hablar propiamente de alfarería romana, ni por la tipología de los hornos ni por las producciones cerámicas, hasta muy finales del siglo I a.C. El contraste con la bahía de Cádiz resulta muy ilustrativo. En este lugar, y dentro de un ambiente general de tradición semita, apegado a las estructuras tradicionales de planta circular u ovalada y pilar central, incluso con detalles técnicos originales durante los siglos III y II a.C. como el llamado "praefurnio escalonado" (Lorenzo y otros 2004), se observa desde mediados del siglo II a.C. la incorporación de soluciones técnicas y/o morfologías fornáceas propias del mundo itálico.

La introducción en la isla de San Fernando de los hornos del tipo I/d de Cuomo di Caprio (planta circular con pasillo central definido por arcos abiertos en el centro de muros paralelos entre sí que dividen la cámara en sentido perpendicular al eje del praefurnium), un sistema de sustentación ajeno totalmente al mundo productivo púnico-gaditano, se retrotrae al menos a la segunda mitad del siglo II a.C. como se constata en el alfar de la calle Pery Junquera, donde una estructura de este tipo se superpone, amortizándolo, a un horno anterior de pilar central (González Toraya y otros 2001). Por otra parte, los hallazgos de la Avenida de Portugal, en el istmo de Cádiz, incluyen una placa perforada de adobe cocido y forma de cuña que ha sido interpretada como parte de un horno de parrilla desmontable 

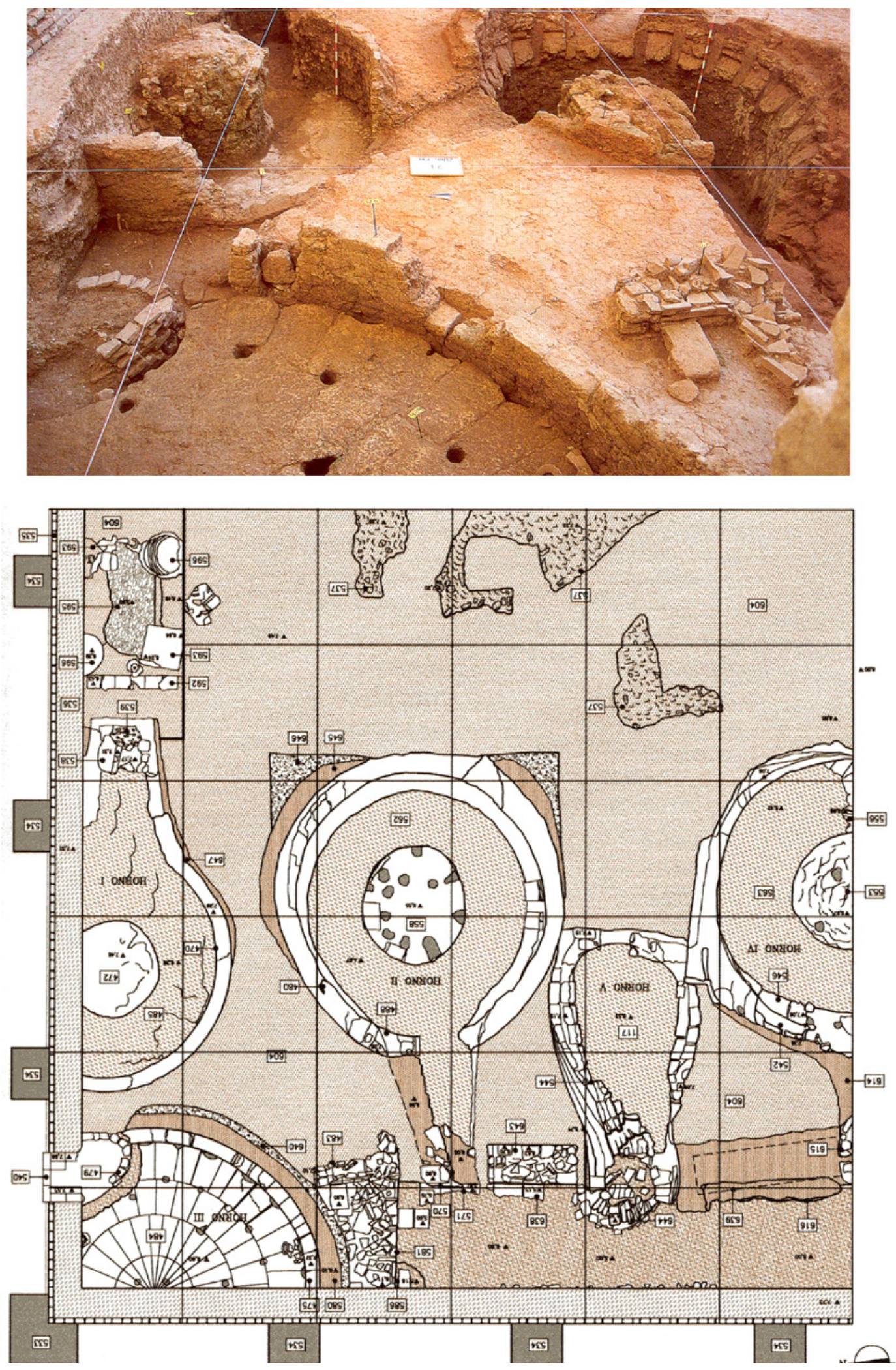

Figura 14: Hornos del alfar del Hospital de las Cinco Llagas (Sevilla), a partir de Tabales 2003.

ISSN: 1133-4525 ISSN-e: 2255-3924 
o "prefabricada", solución técnica propia de ambientes artesanales itálicos de tipo militar, en los que las estructuras productivas se trasladan, evidentemente, con los ejércitos a los que sirven (Bernal y otros 2004). Se trata de una pieza que constituyó en su día una de las ocho que en total conformarían la parrilla de un pequeño horno circular de 1,30 m. de diámetro, aspectos ambos deducidos necesariamente de la morfología y el tamaño de la placa documentada, único elemento conocido de un horno del que tal vez salieran los fallos de cocción de ánforas T-7.3.3.3 procedentes de la misma excavación. Los editores de esta pieza piensan concretamente en el uso en Cádiz durante las últimas dos décadas del siglo I a.C. de hornos similares a los de Lower Nene Valley, Inglaterra (Swan 1984: 65), caracterizados por una forma circular, con pilar central y parrillas prefabricadas y portátiles, realizadas en secciones de cuarto de círculo y apoyadas en vigas o barras radiales.

El horno de planta rectangular de Mesas de Asta (la antigua Hasta Regia), en Jerez de la Frontera, fechado en las décadas finales del siglo I a.C. (González y Barrionuevo 1997: 64) parece responder a esta misma influencia "itálica", a la que se hace responsable de la adopción en el sur de la Península Ibérica de hornos alfareros de esta morfología. Una forma análoga ofrece uno de los hornos más recientemente excavado en El Rinconcillo, esta vez en la bahía de Algeciras, tal vez de fines del siglo I a.C. y relacionado con un contexto artesanal en el que predominan los hornos circulares (Torremocha y otros 2002: 272; cf. para todo lo anterior Bernal y otros 2004).

La utilización de hornos de planta rectangular es frecuente en los ambientes itálicos, siendo los mejor conocidos los del entorno de Brindisi, especialmente el complejo artesanal de Giancola, en Apulia, y los del área de Grossetto, en Toscana, entre los que destaca el conjunto de Albinia (cf. Pallecchi 2007; 2008; 2010). En ambos casos, las estructuras fornáceas, con excepción de un horno circular en Giancola, corresponden a la forma II/b de Cuomo di Caprio: planta rectangular con pasillo central creado por los arcos de una serie de muros perpendiculares al eje del praefurnium. También en ambos establecimientos los hornos rectangulares se encuentran agrupados por parejas cuyos praefurnia se abren a un mismo muro de fachada y dan a un patio de trabajo y alimentación frontal. La disposición "en batería" es similar a la que presentan en la Bética las parejas de hornos de Azanaque-Castillejo (Romo y Vargas 2001) o Arva (Remesal y otros 1997), cuyos praefurnia presentan las bocas englobadas en un mismo muro corrido de "fachada" (fig. 13), mientras que patios o áreas de trabajo fronteras a más de un horno se documentan en el Hospital de las Cinco Llagas de Sevilla (actual Parlamento de Andalucía), donde, en lo excavado (Tabales 2003), los praefurnia se abren a dos muros que configuran una de las esquinas del patio, sugiriendo un espacio cerrado de forma rectangular desde el que podría entretenerse un número desconocido de hornos abiertos en varios frentes (fig. 14). Un modelo "mixto", entre las baterías de hornos unidas por un muro de fachada y los hornos dispuestos a torno a los muros de un patio central, es el que presentan las estructuras de cocción excavadas en El Tejarillo (Alcolea del Río), donde al menos cinco hornos se disponen en línea frente a un pasillo rectangular alargado desde el que se podía acceder a las bocas de todos ellos (Remesal 1983: 119).

En todos los casos citados, nos encontramos ante hornos del tipo "tradicional" presentes en la región desde época protohistórica: los de horno circular con pilar central, en este caso, con parrilla sustentada en arcos. Es evidente que tanto los detalles constructivos de los hornos, los materiales empleados en su factura, como la disposición espacial de los mismos, unos con respecto a otros y a los paramentos y/o estructuras que los delimitan y/o contienen (cf. igualmente el caso de La Catria: Remesal 1977-1978; o de Peñaflor: Bonsor 1989 [1931]: 44, fig. XIII), indican un desarrollo técnico particular del "arte" constructivo en las alfarerías que sólo fue posible en el ambiente de "desarrollo" económico de los primeros siglos del Imperio; pero tampoco nos cabe duda de que, por encima de estas "notas" técnicas que insertan los talleres del interior de la Bética en la misma "maestría" artesanal que fue la responsable de los alfares del sur de la Galia o de la misma Italia, por poner ejemplo de regiones romanas o claramente romanizadas, la persistencia de los hornos de planta circular con pilar central es un rasgo de "personalidad" especial de los alfares del la cuenca del Guadalquivir que de alguna manera mantuvieron o "fosilizaron" determinadas tradiciones del artesanado local previas a la conquista de la región por Roma.

Esta situación o este estado de cosas no puede considerarse, sin embargo, como un rasgo constituyente de la cultura "alfarera" del Guadalquivir ajeno a cambios o a mutaciones de sus elementos constituyentes. A lo largo de los siglos II y III d.C. estructuras de cocción cerámicas diferentes a las tradicionales fueron haciendo su aparición al lado de los tradicionales hornos circulares de pilar central en todo el interior del valle $\mathrm{y}$, sin desplazar del todo estos últimos, contribuyeron a dibujar un panorama más complejo y articulado en el seno de las tradiciones alfareras regionales. 
En la alfarería de Villaseca (Córdoba: de la Peña 1967: 135-137), dos de los cinco hornos conocidos desde antiguo y hoy destruidos fueron de planta rectangular con cámara de cocción dividida en tres naves por dos muros paralelos (similar a tipo II/a de Cuomo di Caprio), en el ejemplar mejor documentado, ignorándose el sistema de sustentación de la parrilla en el caso del segundo horno rectangular. En la alfarería de Cruz Verde, en Brenes (Sevilla), los hornos situados en batería son rectangulares con parrilla apoyada en un muro central, según se aprecia (con dificultad) en las fotografías antiguas de estas estructuras (Ponsich 1974: 309, lám. XIII). En este caso, la última hornada producida por estas estructuras parece haber sido de ladrillos, lo que ha llevado a plantear la posibilidad de una dualidad formal (planta circular vs planta rectangular) basada en el tipo de material cocido en cada horno, siendo los de planta rectangular especialmente aptos, por su geometría, para cocer tégulas y ladrillos. No es más que una suposición que seguramente no tiene en cuenta el carácter polivalente de las alfarerías del Guadalquivir, que producían otros elementos como cerámicas comunes y que, por lo tanto, no debieron estar tan cerradamente especializadas como para necesitar infraestructuras específicas para materiales de construcción. De hecho, hornos de menores dimensiones que fabricaron, no obstante, grandes dolia y lebrillos, así como materiales de construcción, mantuvieron la planta circular, como en el caso del documentado en Cortijo del Río (Marchena), fechado hacia la segunda mitad del siglo II d.C. (Romero Moragas 1987) y sustentado, sin embargo, sobre muretes transversales con arcos que creaban un pasillo central (tipo I/d de Cuomo di Caprio) (fig. 15).

Estas estructuras de la forma I/d son más abundantes en la Andalucía Central y Occidental de lo que pudiera parecer a primera vista $\mathrm{y}$, en conjunto, se sitúan en un marco cronológico que va desde fines del siglo I hasta el IV d.C., con perduraciones incluso hasta el $\mathrm{V}$ d.C. en algunos lugares de la región indicada (El Ruedo, Almedinilla: Muñiz y otros 2000). En el interior de la Bética son dos grandes zonas las que concentran las estructuras de este tipo conocidas hasta hoy: el entorno de Antequera, en la actual provincia de Málaga (Bobadilla: Fernández Rodríguez y otros 2010), y las Subbéticas cordobesas, en el triángulo Almedinilla - Carcabuey - Priego de Córdoba (Muñiz y otros 2000; Lara y Camacho Ruiz 1996; Carmona y Luna 2009, respectivamente), siendo el ejemplar de Marchena (Romero Moragas 1987) el único conocido por ahora fuera de estas áreas, aunque relativamente cercano tanto a la una como a la otra, por lo que puede considerarse como el ejemplo más occidental de todos los documentados hasta la fecha en la región.

En la mayor parte de los casos mencionados estas estructuras, relativamente tardías desde el punto de vista cronológico, presentan una peculiaridad arquitectónica que las singulariza y que, en cierto sentido, demuestra la poca operatividad de las clasificaciones basadas en exclusiva en la planta de la cámara normalmente mejor conservada, la de combustión, y en sus sistemas de soporte. Esta particularidad consiste en la existencia en el eje del pasillo formado por los arcos de un rehundimiento o zanja excavada, que coincide con el eje de la cámara y que deja a los lados dos bancos o escalones sobre los que se apoyan los muros divisorios del espacio interior de la misma. La profundidad de esta depresión central es variable y oscila entre 0,60 m. del horno de Marchena (fig. 15) y los 0,90-1,00 m. de los de Carcabuey y Almedinilla. La presencia de este rehundimiento central debe relacionarse con alguna necesidad de tipo técnico, siendo posible que la fosa funcionase como cenicero, facilitando las labores de limpieza entre cocciones. No obstante, su función primordial debió ser la de aumentar el tiro y el reparto del calor, la eficacia térmica en otras palabras, gracias a que incrementaba el volumen útil en el interior de la cámara sin comprometer la estabilidad general del horno, pues las suspensurae sobre las que descansaba la parrilla no alcanzaban una altura que las haría necesariamente inestables gracias a que se alzaban sobre unos escalones, esto es, las zonas en reserva no afectadas por la fosa central (cf. Juan Tovar 1992).

El empleo de muros transversales como sistema de sustentación de la parrilla, donde existía, o como procedimiento de división interna del espacio para un mejor reparto y circulación del calor generado en el praefurnium, parece una solución típicamente itálica, más allá de la morfología del horno (Coll 2008: 117). La misma procedencia deben tener las mejoras técnicas encaminadas a conseguir la circulación correcta del aire caliente o la creación de espacios más o menos estancos en el recorrido del calor. Éstas se documentan especialmente en áreas de la Tarraconense ampliamente romanizadas y deben haber sido consecuencia de la implantación en la región de colonos o de artesanos a ellos ligados desde fechas muy tempranas. Las claras diferencias en cuanto a la repartición de las tipologías de hornos entre el NE y el SO de la Península hablan a las claras sobre el hecho de que la influencia del elemento externo fue más importante en los desarrollos alfareros de la primera zona que en la segunda (Coll 2009: 197, fig. 4). 


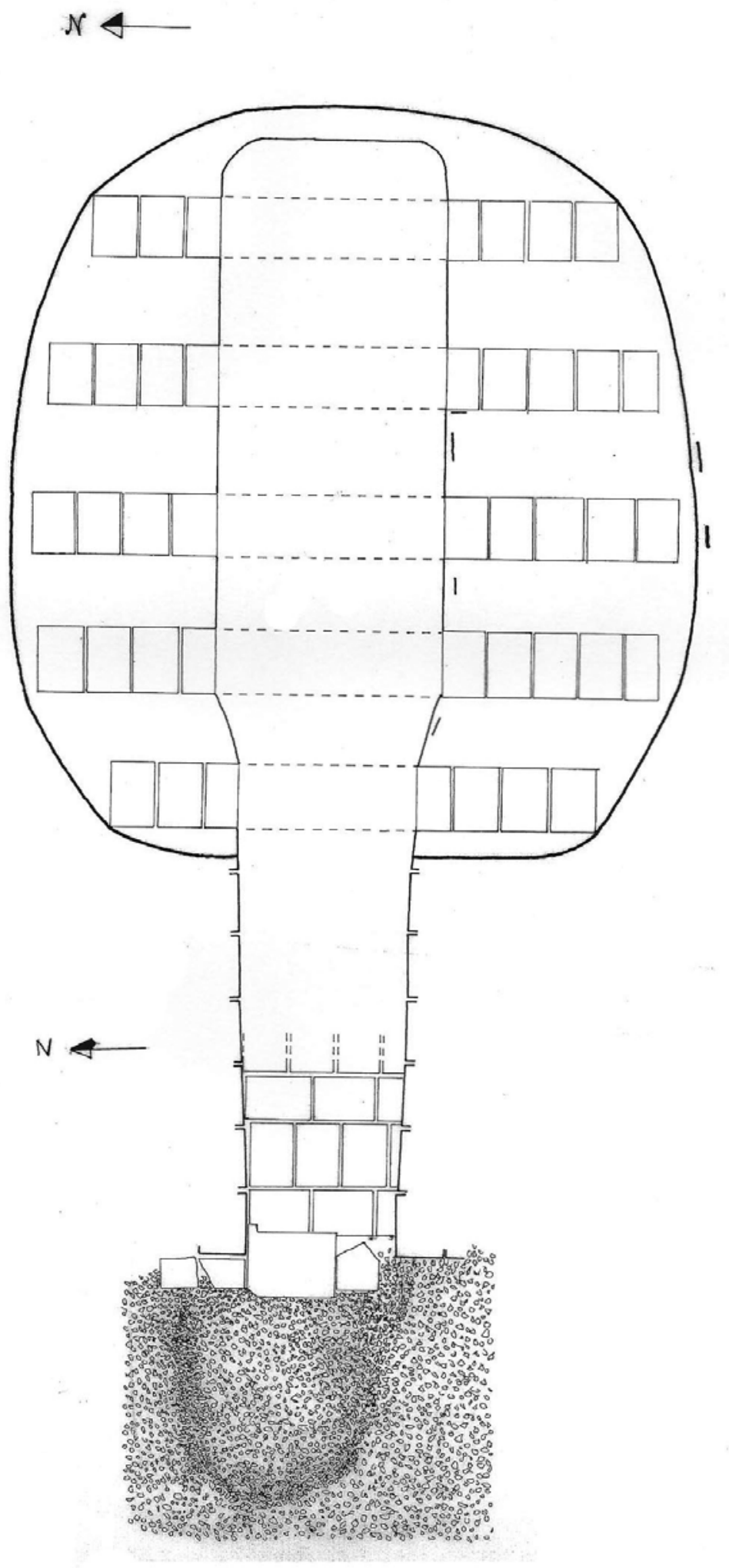

Figura 15: Horno del Cortijo del Río (Marchena, Sevilla), Dibujo de C.

Romero Moragas y E. Conlin Hayes 
Sólo a partir de época flavia, con la efectiva y total romanización del valle del Guadalquivir, las novedades técnicas ligadas al savoir faire del artesanado itálico parecen haberse implantado con alguna amplitud en la región y su periferia inmediata, donde, no obstante, la tendencia a fabricar hornos de planta circular continuó pesando por mucho tiempo, con notables excepciones como el ejemplar de Isla Redonda, al norte de Écija (Hernández Díaz y otros 1951: 84), del tipo II/b de Cuomo di Caprio.

Los trabajos de análisis espacial y de implantación territorial documentan una romanización tardía de las estructuras poblacionales, con la aparición del sistema de villae tan tarde como época flavia (Carrillo e Hidalgo 1990) en zonas relativamente marginales, y no necesariamente lejanas, con respecto al núcleo de vieja romanización de los valles del Guadalquivir, Corbones y Genil. Los hornos de arcos transversales y fosa central se reparten en un área del Conventus Astigitanus, en especial la Subbética, pero también en algunas zonas del entorno de Antequera, en las que la implantación del sistema villático no se hace efectiva hasta los avances de la municipalización flavia, de manera que estos pequeños hornos relacionados con las necesidades de los nuevos establecimientos rurales surgen ya en un ambiente de decidida y aplastante romanización estructural, lo que tal vez explique, más que su supuesta dedicación específica a cerámicas comunes, sus peculiaridades técnicas, frente a un área nuclear de más antigua romanización pero en la que la fuerza de las estructuras vernáculas se habrían hecho sentir hasta más tarde en medio de un ambiente muy mediatizado por las formas organizativas del Imperio Romano. De ello es un buen recordatorio la pervivencia de la onomástica turdetana en los alfares del Guadalquivir precisamente hasta época flavia (Chic García 2001a: 156, 162: un Attita -cf. Urchail Attita f. Chilasurgun de CIL II 1087- en las alfarerías de Las Sesenta, La Mallena o El Berro), o el mantenimiento de formas organizativas rurales ancladas en el pasado prerromano durante los mismos años en el entorno de Carmona o Lora del Río, por poner dos de los ejemplos mejor conocidos (Sáez Fernández 1978; Chic García 1993; 2001b).

\section{BIBLIOGRAFÍA}

ARANCIBIA ROMÁN, A. y ESCALANTE AGUILAR, $M^{a}$ DEL MAR (2006): "La Málaga feniciopúnica a la luz de los últimos hallazgos", Mainake XXVIII: 333-360.
AUBET SEMMLER, Mª.E. (1999): "La secuencia arqueo-ecológica del Cerro del Villar", La cerámica fenicia en Occidente: centros de producción y áreas de comercio, Actas del I Seminario Internacional sobre Temas Fenicios: 40-68. Alicante.

AUBET SEMMLER, M ${ }^{\mathrm{a}}$.E. y otros (1999): Cerro del Villar - I. El asentamiento fenicio en la desembocadura del río Guadalhorce y su interacción con el hinterland. Sevilla.

BELÉN DEAMOS, Ma . (2006): "Ánforas de los siglos VI-IV a.C. en Turdetania", Spal 15: 217-246. http:// dx.doi.org/10.12795/spal.2006.i15.11

BERNAL, D.; LORENZO, L.; EXPÓSITO, J.A.; SÁEZ, A.M.; DÍAZ, J.J. (2004): "Las innovaciones tecnológicas en la alfarería gadirita (s. II a.C.). A propósito del taller anfórico de la Avenida de Portugal", Actas del Congreso Internacional FIGLINAE BAETICAE. Talleres alfareros y producciones cerámicas en la Bética romana (ss. II a.C. - VII d.C.), BAR International Series 1266, II: 621-632. Oxford.

BONSOR, G. (1989) [1931]: Expedición arqueológica a lo largo del Guadalquivir. Écija.

BRONCANO, S. y COLL, J. (1988): "Horno de cerámica ibérico de Casa Grande, Alcalá del Júcar (Albacete)", NAH 30: 189-228.

CARDENETE, R.; GÓMEZ, M.T.; JIMÉNEZ, A.; LINEROS, I.; RODRÍGUEZ, I. (1991): "Excavaciones arqueológicas de urgencia en el solar de la calle Montánchez 4, Carmona (Sevilla)", AAA/1989 (vol. III): 585-591.

CARMONA AVILA, R. y LUNA OSUNA, D. (2009): "Localización de dos hornos hispanorromanos de producción cerámica en la urbanización Los Almendros (Priego de Córdoba)", Antiquitas 21: 125-134.

CARRASCO, J.; PACHÓN, J.A.; PASTOR, M.; NAVARRETE, $M^{a}$. (1987): "Memoria preliminar de la campaña de excavaciones de 1985 en el Cerro de la Mora (Moraleda de Zafayona, Granada)", AAA/1985 (vol. II): 264-270. Sevilla.

CARRILLO DÍAZ-PINÉS J. R. e HIDALGO PRIETO, R. (1990): “Aproximación al estudio del poblamiento romano en la comarca de Palma del Río (Córdoba): La implantación territorial", Ariadna 8: 37-68.

CHIC GARCÍA, G. (1993): "Convecinos en las tierras de Lora del Río. Reflexiones en torno a una nueva inscripción axatiana de época romana", Lora del Río. Revista de estudios locales 4: 7-13.

- (2001a): Datos para un estudio socioeconómico de la Bética. Marcas de alfar sobre ánforas olearias (2 vols.), Écija. 
- (2001b): "Religión, territorio y economía en la Carmona romana", Carmona Romana. II Congreso de Historia de Carmona: 465-476. Carmona (Sevilla).

CHIC GARCÍA, G. y GARCÍA VARGAS, E. (2004): "Alfares y producciones cerámicas en la provincia de Sevilla. Balance y perspectivas", Actas del Congreso Internacional FIGLINAE BAETICAE. Talleres alfareros y producciones cerámicas en la Bética romana (ss. II a.C. - VII d.C.), BAR International Series 1266, I: 279-348. Oxford.

COLL CONESA, J. (2000): “Aspectos de tecnología de producción de la cerámica ibérica”, III Reunió sobre Economía en el Món Ibèric (Sagvntvm Extra-3): 191-209.

- (2008): "Hornos romanos en España. Aspectos de morfología y tecnología", Cerámicas hispanorromanas: un estado de la cuestión: 113-126. Cádiz.

CONTRERAS, F.; CARRION, F.; JABALOY, E. (1983): "Un horno de alfarero protohistórico en el Cerro de los Infantes (Pinos Puente, Granada)", XVI CNA: 533-538. Zaragoza.

CUOMO DI CAPRIO, N. (1971-1972): "Proposta di classificazione delle fornaci per ceramica e laterici nell'area italiana. Dalla Preistoria a tutta 1'epoca romana", Sibrium 11: 371-461.

- (2007): Ceramica in Archeologia 2. Antiche tecniche di lavorazione e moderni metodi di indagine (Studia Archaeologica 144). Roma.

CURIÁ, E.; DELGADO, A.; FERNÁNDEZ, A.; PÁRRAGA, M. (2000): "La organización de la producción de cerámica en un centro colonial fenicio: el taller alfarero del siglo VI a.n.e. del Cerro del Villar (Málaga)", IV Congreso Internacional de Estudios Fenicios y Púnicos, vol. IV: 1475-1485. Cádiz.

DE FRUTOS REYES, G. y MUÑOZ VICENTE, A. (1994): "Hornos púnicos de Torre Alta (San Fernando, Cádiz)", Arqueología en el entorno del Bajo Guadiana: 393-314. Huelva.

DE LA PEÑA, J. (1967): “Alfares y marcas del valle medio del Guadalquivir", AEspA 40: 129-137.

DELGADO HERVÁS, A. (2008): “Cerro del Villar, de enclave comercial a periferia urbana: dinámicas coloniales en la bahía de Málaga entre los siglos VIII y VI a.c.", Contactes. Indígenes i fenicis a la Mediterrània occidental entre els segles VIII $i$ VI ane.: 69-88. Alcanar (Tarragona).

ESCACENA CARRASCO, J.L. (1989): “Los turdetanos o la recuperación de la identidad perdida", Tartessos. Arqueología Protohistórica del Bajo Guadalquivir: 433-476. Sabadell.
- (1992): "Indicadores étnicos en la Andalucía prerromana”, Spal 1: 321-343. http://dx.doi.org/10.12795/ spal.1992.i1.16

ESCACENA CARRASCO, J.L. y GARCÍA FERNÁNDEZ, F.J. (e.p.): "La Sevilla protohistórica", Hispaniae Urbes. Investigaciones arqueológicas en ciudades históricas. Sevilla.

FALSONE, G. (1981): Struttura e origine orientale dei forni da vasaio di Mozia (Studi Monografici I). Palermo.

FERNÁNDEZ, F.; CHASCO, R.; OLIVA, D. (1979): "Excavaciones en El Cerro Macareno. La Rinconada. Sevilla (Cortes E-F-G. Campaña 1974)", NAH 7: 9-93.

FERNÁNDEZ, L.F.; ROMERO, M.; ARCAS, A. (2010): "El complejo alfarero romano del Arroyo Villalta: Bobadilla, Antequera ( Málaga)”, Romula 9: 177-200.

FERRER ALBELDA, E. (1998): "Suplemento al mapa paleoetnológico de la Península Ibérica: los púnicos de Iberia", RSF XXVI (1): 31-54.

- (2004): "Sustratos fenicios y adstratos púnicos. Los bástulos entre el Guadiana y el Guadalquivir", Huelva Arqueológica 20: 281-298.

FERRER ALBELDA, E. y GARCÍA FERNÁNDEZ, F.J. (2002): "Turdetania y turdetanos: contribuciones a una problemática historiográfica y arqueológica", Colonizadores e indígenas en la Península Ibérica (Mainake XXIX): 133-151. Málaga.

- (2008): "La cerámica turdetana", Cerámicas hispanorromanas. Un estado de la Cuestión: 202-219. Cádiz.

GAGO, Mª H.; CLAVAÍN, I.; MUÑOZ, A.; PERDIGONES, L.; DE FRUTOS, G. (2000): "El complejo industrial de salazones gaditano de Camposoto, San Fernando (Cádiz): estudio preliminar", Habis 31: 37-61.

GARCÍA FERNÁNDEZ, F.J. (2007): "Etnología y etnias de la Turdetania en época prerromana", $\mathrm{Cu}$ PAUAM 33: 117-143.

- (e.p.): "Tartesios, túrdulos, turdetanos. Realidad y ficción de la homogeneidad étnica de la Bética romana", Revisiones de Historia Antigua VII. Romanización, fronteras y etnias en la Roma antigua: el caso hispano. Vitoria.

GARCÍA FERNÁNDEZ, F.J. y GARCÍA VARGAS, E. (2010): "Entre gaditanización y romanización: repertorios cerámicos, alimentación e integración cultural en Turdetania (siglos III-I a.C.)", "De la cocina a la mesa”. IV Reunión de economía en el primer milenio a.C. (Sagvntvm Extra-10): 141-166. GARCÍA FERNÁNDEZ, F.J. y FERRER ALBELDA, E. (2010): "Das turdetanische Emporion Spal. Der 
punische Handelsverkehr im vorrömischen Sevilla (5. - 2. Jahrhundert v. Chr.)", MM 52: 52: 335-374.

GARCÍA VARGAS, E. (1996): "La producción anfórica en la bahía de Cádiz durante la República como índice de romanización", Habis 27: 49-62.

- (2004): “La romanización de la 'industria' púnica de las salazones en el sur de Hispania", Las industrias alfareras y conserveras fenicio-púnicas de la Bahía de Cádiz, XVI Encuentros de Historia y Arqueología: 101-129. Córdoba.

- (2009): "Las ánforas republicanas de Hispalis (Sevilla) y la "cristalización" del repertorio provincial”, Estudios de Prehistoria y Arqueología en homenaje a Pilar Acosta Martínez: 437-464. Sevilla.

GARCÍA VARGAS, E. y BERNAL CASASOLA, D. (2008): “Ánforas de la Bética”, Cerámicas hispanorromanas. Un estado de la Cuestión: 661-687. Cádiz.

GARCÍA VARGAS, E. y GARCÍA FERNÁNDEZ, F.J. (2009): "Romanización y consumo: cambios y continuidades en los contextos cerámicos de Hispalis en épocas turdetana y romano-republicana", Spal 18: 131-165. http://dx.doi.org/10.12795/spal.2009. i1 18.08

GONZÁLEZ ACUÑA, D. (2011): Forma Vrbis Hispalensis. El urbanismo de la ciudad romana de Hispalis a través de los testimonios arqueológicos. Sevilla.

GONZÁLEZ, RODRÍGUEZ, R. y BARRIONUEVO CONTRERAS, F. (1997): "Intervenciones de Urgencia en el entorno inmediato del yacimiento arqueológico de Mesas de Asta (Jerez de la Frontera), $A A A / 1995$ (vol. III): 63-66. Sevilla.

GONZÁLEZ, B.; TORRES, J.; LAGÓSTENA, L.; PRIETO, O. (2001): “Los inicios de la producción anfórica en la bahía gaditana en época republicana: la intervención de urgencia en la Avda. Pery Junquera (San Fernando, Cádiz)", Congreso Internacional Ex Baetica Amphorae. Conservas, aceite y vino de la Bética en el Imperio Romano: 175-185. Écija.

HERNÁNDEZ DÍAZ, J.; SANCHO CORBACHO, A.; COLLANTES DE TERÁN, F. (1951): Catálogo Arqueológico e Histórico de la Provincia de Sevilla, vol. IV. Sevilla.

JIMÉNEZ FLORES, A.Ma . y GARCÍA FERNÁNDEZ, F.J. (2006): "In vino humanitas (y II): vino y cultura en la Turdetania prerromana", Habis 37: 125-144.

JUAN TOVAR, L.C. (1992): “Alfares y hornos de la Antigüedad en la Península Ibérica. Algunas observaciones en torno a su estudio", Tecnología de la cocción cerámica desde la Antigüedad a nuestros dias: 65-85. Agost (Alicante).
LARA FUILLERAT, J.M. y CAMACHO CRUZ, C. (1996): "La Alcantarilla" (Carcabuey, Córdoba), una nueva instalación alfarera en las Subbéticas: aproximación a su medio físico y su estructura económica", Antiquitas 7: 69-92.

LORENZO, L.; SÁEZ, A.M.; DÍAZ, J.J.; EXPÓSITO, J.A.; BERNAL, D. (2004): "Los hornos púnicos de praefurnium escalonado (ss. III y II a.C.): reflexiones a raíz del alfar de La Milagrosa (San Fernando, Cádiz)", Actas del Congreso Internacional FIGLINAE BAETICAE. Talleres alfareros y producciones cerámicas en la Bética romana (ss. II a.C. - VII d.C.), BAR International Series 1266, II: 607-620. Oxford.

LUZÓN NOGUÉ, J.Mª (1973): Excavaciones en Itálica. Estratigrafía en el Pajar de Artillo (EAE 78), Madrid.

MOLINOS, M.; SERRANO, J.L.; COBA, B. (1990): "Excavaciones arqueológicas en el asentamiento de 'La Campiña'. Marmolejo, Jaén”, AAA/1988 (vol. III): 197-203. Sevilla.

MOLINOS MOLINOS, M. y otros (1994): Un problema de fronteras en la periferia de Tartessos: Las Calañas de Marmolejo. Jaén.

MORA VICENTE, G.M. y ROMO SALAS, A.S. (2006): "Intervención arqueológica de urgencia en el Palacio Arzobispal de Sevilla. Sectores de Archivo y Tribunal. Primera fase de los trabajos. Sondeos I-II-IV. Aportaciones a la Sevilla republicana", $A A A / 2003$ (vol. III, 2): 179-196. Sevilla.

MUÑIZ, I.; LARA, J.; CAMACHO, C. (2000): "Sobre alfares, silos y almazaras en la villa romana de El Ruedo, Almedinilla, Córdoba", Antiquitas 11: 233266.

ORTIZ NAVARRETE, A. y CONLIN HAYES, E. (e.p.): "Actividad arqueológica preventiva en c/ Doctor Fleming 13-15 de Carmona (Sevilla)", AAA/2007.

PELLICER CATALÁN, M. (1998): "Los cortes estratigráficos de Itálica y su contribución al estudio de la dinámica histórico-cultural del yacimiento", Boletín de Bellas Artes 26: 143-186.

PALLECCHI, S. (2007): "Le fornaci da anfore di Giancola (Brindisi) in età repubblicana. Un caso di studio", Le fornaci e le anfore di Albinia. Primi dati su produzioni e scambi dalla costa tirrenica al mondo gallico: 181-188. Bologna.

- (2008): "Le fornaci romane di Albinia: identificazione delle unità funzionali e prima ricostruzione delle linee di produzione", Materiali per Populonia 7: 323-338. Pisa. 
- (2010): "Le grandi manifatture di anfore tra tarda repubblica e impero, Rei Cretarice Romance Favtorvm Acta 41: 611-620.

PONSICH, M. (1974): Implantation rurale antique sur le Bas-Guadalquivir, vol. I. Madrid.

RAMÓN, R.; SÁEZ, A.; SÁEZ, A.M.; MUÑOZ, A. (2007): El taller alfarero tardoarcaico de Camposoto (San Fernando, Cádiz). Sevilla.

REMESAL RODRÍGUEZ, J. (1977-1978): "Economía oleícola bética. Nuevas formas de análisis", AEspA 50/51: 87-142.

- (1983): "Transformaciones en la exportación del aceite bético a mediados del siglo III d. C.", Producción y comercio del aceite en la Antigüedad. Segundo Congreso Internacional: 115-131. Madrid.

RODRÍGUEZ RODRÍGUEZ, I. (2001): "Las áreas artesanales: los alfares", Carmona Romana. II Congreso de Historia de Carmona: 311-320. Carmona (Sevilla).

ROMERO MORAGAS, C. (1987): "Un horno de cerámica común romana en Marchena (Sevilla)", $A A A / 1985$ (vol. III): 285-287. Sevilla.

ROMO SALAS, A. y VARGAS JIMÉNEZ, J.M. (2001): “Azanaque (Lora del Río, Sevilla). Evidencias arqueológicas de un centro de producción anfórica", Congreso Internacional Ex Baetica Amphorae. Conservas, aceite y vino de la Bética en el Imperio Romano: 405-418. Écija.

RUIZ MATA, D. (1998): "Turdetanos: origen, territorio y delimitación del tiempo histórico", REIb 3: 153-221.

RUIZ MATA, D. y CÓRDOBA ALONSO, I. (1999): "Los hornos turdetanos del Cerro Macareno. Cortes H.I y H.II", XXIV CNA: 95-105. Cartagena.

RUIZ ZAPATERO, G. y ÁLVAREZ-SANCHÍS, J.R. (2002): "Etnicidad y Arqueología: tras la identidad de los vettones", Spal 11: 253-275. http://dx.doi. org/10.12795/spal.2002.i11.13

SÁEZ FERNÁNDEZ, P. (1978): "Las centurias de la Bética", Habis 9: 255-272.
SÁEZ ROMERO, A.M. (2004): "El alfar tardopúnico de Torre Alta. Resultados de las excavaciones de 2002-2003, Actas del Congreso Internacional FIGLINAE BAETICAE. Talleres alfareros y producciones cerámicas en la Bética romana (ss. II a.C.- VII d.C.), BAR International Series 1266, II: 699-702. Oxford.

- (2008): La producción cerámica en Gadir en época tardopúnica (siglos -III/-I), BAR International Series 1812 (2 vols.). Oxford.

- (2011): "Alfarería en el Extremo Occidente fenicio. Del renacer tardoarcaico a las transformaciones helenísticas", Yõserim: La producción alfarera fenicio-púnica en Occidente (XXV Jornadas de Arqueología Fenicio-Púnica): 49-106. Ibiza.

SÁEZ, A.; MONTERO, A.; TOBOSO, E.J. (2004): "Un antecedente centro-mediterráneo al complejo alfarero púnico de Torre Alta (San Fernando, Cádiz)", Las industrias alfareras y conserveras fenicio-púnicas de la Bahía de Cádiz, XVI Encuentros de Historia y Arqueología: 201-236. Córdoba.

SAYAS BENGOECHEA, J.J. (1989): “Colonización y municipalización bajo César y Augusto. Hispania Ulterior", Aspectos de la colonización y municipalización de Hispania (Cuadernos Emeritenses 1): 33-70. Mérida.

SWAN, V. G. (1984): The pottery kilns of Roman Britain. Londres.

TABALES RODRÍGUEZ, M.A. (2003): "El complejo alfarero localizado bajo el Parlamento de Andalucía", Arqueología y Rehabilitación en el Parlamento de Andalucia. Investigaciones arqueológicas en el Antiguo Hospital de las Cinco Llagas de Sevilla: 139-162. Sevilla.

TORREMOCHA, A.; TOMASSETTI, J.M.; JIMÉNEZ-CAMINO, R. (2002): "Excavación Arqueológica de Urgencia en la Avenida de la Estación (Algeciras) y hallazgo de los restos de un horno alfarero de época romana", Caetaria 3: 271-272. 